\title{
Global Competition for Leadership Positions in Standards Development Organizations
}

\author{
Justus Baron* \\ Northwestern University
}

\author{
Olia Kanevskaia ${ }^{\dagger}$ \\ KU Leuven
}

March 31, 2021

\begin{abstract}
Increasing participation of Chinese companies in many global Standard Development Organizations (SDO) has fueled global competition for influence over the development of critical Information and Communication Technology (ICT) standards. SDOs face increasing expectations to increase the representation of Chinese and other non-Western nationals in their leadership. Many Western governments and stakeholders, however, view the rapidly rising influence of Chinese firms, and especially Huawei, as a source of growing concerns. These tensions highlight the importance of the impartiality of global SDOs' leadership for the trustworthiness of ICT standards. Our empirical analysis reveals that while attendees have become increasingly diverse, traditional incumbent stakeholder categories and Western nationals occupy an outsized proportion of SDO leadership positions. Affiliates of Huawei and other leading competitors for leadership in ICT standardization are also more likely to be appointed to leadership positions. Huawei furthermore rapidly catches up with its Western competitors, in part through recruiting large numbers of experienced SDO participants. Individuals are appointed to leadership positions because of their experience and individual qualifications, not because of their affiliation. While the importance of individual experience and social ties within an SDO community may act as a check on commercial stakeholders' influence within SDOs, preventing individual companies or groups of aligned interests to acquire outsized influence over SDOs requires explicit provisions for the balancing of different interests.
\end{abstract}

JEL-Classification: L15, L16, O33

${ }^{*}$ Research Associate, Searle Center on Law, Regulation, and Economic Growth, Northwestern University Law School, 375 East Chicago Avenue, Chicago, IL 60611. E-mail: justus.baron@law.northwestern.edu. Research at the Center on Law, Business, and Economics has benefited from financial support from Qualcomm and Intel, among other sponsors. The authors are grateful to Bernhard Ganglmair, Tim Simcoe, and Emanuele Tarantino for permission to use IETF-related data that they provided.

${ }^{\dagger}$ Postoctoral Fellow, KU Leuven Center for IT and IP Law \& Global Postdoctoral Emile Noel Fellow, The Jean Monnet Center for International and Regional Economic Law \& Justice, NYU School of Law. E-mail: olia.kanevskaia@kuleuven.be 
Keywords: Standards Development Organizations (SDO), Governance, Committee Chair Selection, Huawei, Catching-Up, Global South 


\section{Introduction}

For decades, there has been fierce competition for leadership in the development of Information and Communication Technologies (ICT) standards. Traditionally, this competition has been driven by the commercial interests of large, and often multinational corporations. More recently geopolitical considerations have added to the traditional commercial rivalry. Standard Development Organizations (SDOs) actively seek to diversify their membership, and particularly their leadership, which continue to be largely dominated by individuals from Western countries. Relatively low representation of individuals from developing countries in SDO leadership, and in particular individuals from China, contrasts with the increasing contribution that Chinese organizations make to ICT standards development. At the same time, the rapid ascension of Huawei Technologies and other large Chinese organizations and their attempts to seek greater influence in ICT standardization raised concerns in Western countries, in particular due to the importance of ICT standards for critical security and commercial interests. ICT standards can have significant political implications and can be used as tools of national or regional industrial policy through which certain values and political views are disseminated (Bradford, 2020; Gamito, 2021, 2018).

Chinese companies, and in particular Huawei, have made significant contributions to the development of important ICT technologies and standards, such as $5 \mathrm{G}$, the latest generation of wireless communication technology standards. However, multiple cybersecurity incidents allegedly linked to Huawei ${ }^{1}$ (Shoebridge, 2018) as well as the recent Huawei-driven attempts at the International Telecommunications Union (ITU) to reform the Internet with the "New IP" protocol(Hoffman et al., 2020) and to steer the development of facial recognition standards ${ }^{2}$ prompted governments of Western countries, in particular the US, to take a critical stance. Measures intended to curb the influence of Huawei and other Chinese entities on ICT standards development range from the prohibition for Federal Agencies to procure telecommunications equipment and services supplied by Chinese manufacturers ${ }^{3}$ to Huawei's listing on the US Export Administration Regulation (EAR) entity list, ${ }^{4}$ to prohibiting it from supplying components for essential communications infrastructure. ${ }^{5}$

Appointments of individuals to leadership positions have recently become a focus of this debate. Huawei-affiliates are increasingly being appointed or considered for leadership

\footnotetext{
${ }^{1}$ See also FCC 19-121 in the Matter of Protecting Against National Security Threats to the Communications Supply Chain Through FCC Programs (WC Docket No. 18-89), Huawei Designation (PS Docket No. 19-131), ZTE Designation (PS Docket No. 19-352) release November 26, 2019; European Parliament, 2019/2575 (RSP) Resolution, Security threats connected with the rising Chinese technological presence in the EU and possible action on the EU level to reduce them

${ }^{2}$ https://www.ft.com/content/c3555a3c-0d3e-11ea-b2d6-9bf4d1957a67

${ }^{3}$ H.R. 4747, 115th Cong. (2018); Federal Acquisition Regulation: FAR Case 2018-017, Prohibition on Contracting for Certain Telecommunications and Video Surveillance Services or Equipment (August 7, 2019) at 48 C.F.R. pts. 1, 3, 12, 13, 39, \& 52. H.R. 5515, 115 Cong. (2017-2018); John S. McCain National Defense Authorization Act for Fiscal Year 2019, H.R. 5515, 115th Cong. (August 13, 2018) Sec $889(\mathrm{a})(\mathrm{a})(\mathrm{B})$

${ }^{4}$ Addition of Certain Entities to the Entity List and Revision of Entries on the Entity List, 84 Fed. Reg. 43493 (August 19, 2019) at 15 C.F.R. pt. 744

${ }^{5} 85$ Fed. Reg. 42665 Federal Acuiqisition Regulation: Prohibition on Contracting With Entities Using Certain Telecommunications and Video Surveillance Services or Equipment (July 14, 2020) at 48 C.F.R. pts. $1,3,12,13,39, \& 52$
} 
positions that could influence standardization decisions within the most relevant global ICT standards bodies: to illustrate, at least two Huawei employees were figuring among the plausible contenders for the chair of the Internet Engineering Task Force (IETF). ${ }^{6}$ The surge in the number of leadership positions held by Huawei, such as working group chairs and vice-chairs, raised concerns that the incumbents may support bias in standardization processes by favouring their company's proposals or opposing rival proposals and, more generally, allow Huawei to gain an undue competitive advantage over Western commercial and strategic interests. ${ }^{7}$ At the same time, there is ongoing debate whether SDOs are doing enough to diversify their leadership and allow for a better representation of non-Western countries.

To this day, little attempts have been made to substantiate the abovementioned concerns with empirical evidence. Allegations of Huawei's supposed lead in different aspects of ICT standardization are based on misleading or uninformative indicators of leadership such as counts of declared Standard Essential Patents (SEP). ${ }^{8}$ To our knowledge, there has been no systematic study of appointments to leadership positions in SDOs, which would provide empirical evidence on the extent of representation of Chinese individuals and Huawei affiliates in SDO leadership. Consequently, it is difficult to assess whether leadership appointments are biased towards Western individuals, as well as whether there are any strategies of pursuing leadership positions which would set Huawei apart from large contributors to standards development from Western countries. More generally, there is a lack of empirical research on the factors determining the number of SDO leadership positions held by a company, as well as on the extent to which these factors are shaped by the rules and institutional norms of SDOs. In particular, these rules and norms determine to what extent individuals are appointed because of their personal experience, motivation, and qualifications, or because of the commercial interests that they represent. Understanding these features is crucial, since they condition whether and how SDO leadership positions can be misused in furtherance of a company's agenda.

\footnotetext{
${ }^{6}$ https://www.centr.org/news/blog/ietf109-new-chair.html

${ }^{7}$ In a U.S. Senate Hearing, Christopher Krebs, then Director of the Cybersecurity and Infrastructure Security Agency, testified: "Foreign nationals representing foreign companies, including Chinese companies China Mobile Communications Corporation and Huawei, hold key leadership positions on the ITU and 3GPP standards bodies for 5G. These individuals may be able to influence ITU and 3GPP to adopt standards that favor their own companies and put U.S. companies at a competitive disadvantage, potentially affecting their ability to compete in the market for years and increasing the United States' reliance on foreign technology." https://www.judiciary.senate.gov/imo/media/doc/Krebs\%20Responses\%20to\%20QFRs.pdf In a proposed legislative amendment, U.S. Senator Coons stated that "A growth in the representation of Chinese companies and interests in certain standards-setting bodies, including by securing leadership positions in them, could lead to further dominance and lack of balance in standards-setting bodies and increase the risk that block-voting will make it difficult for these bodies to ensure balanced and consensusbased decisions." Section 305 of Senate Bill 687 attempts to address these concerns by promoting U.S. leadership in international SDOs. These concerns echo allegations or findings of abuses of chair positions by other companies; see American Society of Mechanical Engineers v. Hydrolevel Corporation, 456 US 556 (1982) and, later, Trueposition, Inc. v. LM Ericsson Tel. Co. (Jan 6, 2012), No. 11-4574, 2012 WL $33075[2012]$

${ }^{8}$ Counts of patents and "contributions" have been criticized, because prone to manipulation, and insufficiently informative of the quality of the inventions and contributions. See for instance the statement of the Hudson Institute Forum for Intellectual Property on 5G Technological Leadership, available at https://s3.amazonaws.com/media.hudson.org/Hudson_5G\%20Technological\%20Leadership.pdf
} 
This Article empirically analyzes leadership appointments in the working groups of four of the most prominent SDOs in the ICT sector, namely namely the Third Generation Partnership Project (3GPP), OneM2M global partnership project, IETF and the Institute of Electrical and Electronics Engineers' working group for Wireless Local Area Network Standards (IEEE 802.11). We created a database with over 340,000 individual meeting attendance records, and nearly 20,000 observations of working group leadership (individuals holding the chair during a working group meeting). We have collected rich data on more than 45,000 individuals in the dataset, including information at the level of the individual (including country of residence, past experience as attendee and chair, seniority within the SDO, and patent inventorship), as well as characteristics of the primary affiliation (including entity type, number of SDO memberships, extent of participation in this SDO, number of declared SEP and technical contributions to SDOs). We can thus assess for each SDO which individual and affiliation-level factors matter for appointments to working group chair positions, and the relative importance of each; i.e. the relative weight of who you are vs. who you work for. We separately identify the two factors using affiliation changes resulting from mergers, acquisitions and spinoffs; as well as vacancies in relevant working group chair positions as instrument for appointments. We interpret the empirical findings on the determinants of SDO chair appointments in light of these SDOs' institutional rules and informal practices. In particular, we distinguish betwen SDOs that explicitly expect individual participants to represent certain stakeholders (3GPP, OneM2M) and SDOs encouraging or even requiring individuals to participate in their individual capacity (IEEE SA, IETF) - even though these individuals are generally remunerated for this work by employers that have particular interests in standards development.

We document continued over-representation of individuals from Western countries in SDO leadership positions. While the extent of this over-representation gradually erodes, as new chair vacancies are filled from substantially more diverse pools of candidates and individuals from non-Western countries quickly catch up in terms of relevant SDO experience, Western individuals continue to be more likely to be appointed than similarly experienced individuals from other countries. This difference however is not specific to China or even to developing countries, as highly developed Asian countries such as Japan and Korea are even more under-represented in new appointments. In spite of the over-representation of Western countries, Huawei has acquired a large number of SDO leadership positions (often with Western individuals). Controlling for experience and other individual characteristics, Huawei affiliates are not more or less likely than affiliates of other large companies to be appointed to leadership positions; however, more than any other organization, Huawei is recruiting individuals with relevant SDO experience from other companies. These individuals owe their leadership positions in SDOs to their personal characteristics and experience, which are generally much more important for appointments to SDO working group chair positions than affiliation characteristics. The importance of individual experience and qualifications for appointments may at least partly shield the SDO from outside influence, as companies cannot fill leadership positions at will, and must instead work with longstanding and respected members of an SDO's community.

Our findings shed light on significant differences between the SDOs in our sample. While individual-level experience generally is the most important predictor of appointments to chair poistions, affiliation characteristics matter more at IETF than at 3GPP for predicting whether an individual is appointed to chair a working group. Given the IETF's emphasis on 
individual participation, one may have expected that affiliiation with a large company plays no or a lesser role for appointments to chair positions at IETF. Nevertheless, "donating" their employees' time to serve the SDO is a costly investment for employers, and our findings suggest that this investment is only profitable for companies with significant stakes in the SDO's standards. While these incentives are also at play at 3GPP and other SDOs based on explicit representation of an organization, these SDOs also emphasize the need for a balanced representation of different stakeholders. We conclude that encouraging individuals to represent their personal views is unlikely to act as an effective check on commercial stakeholders' influence within SDOs, and that preventing individual companies or groups of aligned interests to acquire outsized influence over SDOs requires explicit provisions for the balancing of different interests.

\section{Literature Review}

The specific research questions of our paper have so far only been analyzed in a small body of descriptive or qualitative studies. Some studies have analyzed shifts in Chinese industrial and standardization policies and strategies in a qualitative approach (Gibson, 2007; Ernst, 2011; Murphree and Breznitz, 2018) and observed a trend of increasing participation by Chinese and other Asian individuals in IETF (Contreras, 2014). More recent scholarship studied the increasing number of Chinese candidates suggested for leadership positions in the standardization sector of the International Telecommunications Union (ITU) as well as a large number of Chinese individuals holding leadership positions in this SDOs' studies groups on Artificial Intelligence (AI) (Gamito, 2021).

Scholarship on SDOs more broadly has analyzed how membership and decision-making processes of SDOs influence standardization outcomes (Goerke and Holler, 1995; Lehr, 1996; Werle, 2001; Bonatti and Rantakari, 2016). Some literature linked composition of SDOs' working groups and the quality of their standards (Simcoe, 2012; Wen et al., 2014). Detailed case studies examined the membership, processes and institutional evolution of a single SDO, such as ISO (Murphy and Yates, 2009; Delimatsis, 2018), IEEE (Zingales and Kanevskaia, 2016), and W3C (Halpin, 2017). More recently, Baron et al. (2019) offered a comparative analysis of governance rules of 17 SDOs, and observed significant heterogeneity in SDOs' governance architecture, including leadership election processes.

Past research has also focused on competition and coordination among firms in SDOs (Farrell and Saloner, 1988; Leiponen, 2008; Farrell and Simcoe, 2012), and has empirically examined companies' motives to participate in SDO processes (Blind and Mangelsdorf, 2016; Blind et al., 2020). A large share of scholarship on the dynamics of participation within SDOs has been devoted to the relationship between standardization and patenting, in particular regarding the licensing of Standard Essential Patents (SEPs) (e.g. (Lerner and Tirole, 2015; Rysman and Simcoe, 2008; Gandal et al., 2004; Lemley and Shapiro, 2007).

In this paper, we focus on two dimensions of participation in SDOs that have received comparably limited attention in the literature. First, the vast majority of the empirical research on contemporaneous standards development focuses on firm strategies, neglecting the study of the determinants of individuals' participation in SDOs. Historical research (Russell, 2014; Yates and Murphy, 2019) however highlights that standard development 
is traditionally characterized by a set of norms and rules that are widely shared among individual participants; suggesting that individual considerations importantly contribute to determine the outcome of standardization decisions. Ganglmair et al. (2018) analyze the process of protocol development at IETF, and analyze the role of individual authors' experience for technical decision-making. A particularly relevant individual-level factor is the social capital that individuals acquire through their participation in SDOs (Isaak, 2006). Dokko and Rosenkopf (2010) examine the role of this social capital for these individuals' labor market mobility. Other empirical studies of individual SDO participants have focused on the role that inventor participation plays for the declaration of patented technologies as standard-essential (Kang and Motohashi, 2015); as well as the incentives of researchers to patent and participate in standards development (Blind et al., 2018). We extend this analysis by focusing on an individual's potential to acquire a leadership position in an SDO working group. We also extend the findings of Dokko and Rosenkopf (2010) by demonstrating how the portability of individuals' social capital acquired in SDOs depends on the SDO's governance.

To the best of our knowledge, how individuals respond to potential tensions between the expectations of their employers and their peers in the SDO has not yet been formally studied. Husted and Michailova (2010) study dual-allegiance of individuals in collaborative R\&D and the pressure of firms' employees to show loyalty to their employer as well as to their collaborators. This pressure can also be traced in SDOs where individuals holding leadership positions, usually volunteers, have allegiance both to their affiliations and the SDO and may find themselves in a situation of a conflict of interests. (Werhane and Doering, 1995) analyze such a conflict of interests by an SDO working group chair at the American Society of Mechanical Engineers (ASME). Some studies suggest that volunteers in standards development committees should be held to high ethical standards and subjected to a stricter control to prevent abuse of SDO processes (Marpet, 1998).

Second, while existing empirical studies at the firm level have analyzed determinants of different strategies, such as acquisition of membership in an SDO or SDO committee (Blind and Mangelsdorf, 2016), attending SDO meetings (Fleming and Waguespack, 2009), or making technical contributions to standards development (Fischer and Henkel, 2013), there has been - to the best of our knowledge - no systematic empirical analysis of the acquisition of leadership positions in SDOs (such as chairs of working groups). Chairs of the working groups and governance bodies hold considerable power: they are responsible for the overall management and administration of the committee concerned, serve as the first stage of appeal or investigation processes into breaches of SDOs' procedural rules, and take such pivotal decisions as whether consensus has been achieved or a vote should be conducted. In some cases, chairs may delay or even stall their working groups' discussion (Harcourt et al., 2020; Yates and Murphy, 2019). A position of a chair may thus be highly advantageous for companies actively participating in standards development, and may allow them to exert significant influence on the outcome of standardization decisions. Baron et al. (2021b) study the role of gender for individuals' appointments to leadership positions at one SDO (IETF). However, there has so far been no study that has examined firm strategies in pursuit of SDO leadership positions, let alone linked the empirical findings to a particular model of SDO governance. 


\section{Institutional Background}

\subsection{SDO institutional models}

SDOs share some internationally accepted governance features, such as consensus, openness and transparency (Kanevskaia, 2020). These features are further concretisized in the SDOs operational frameworks in a way that serves their membership and is entrenched in their cultural traditions, which demonstrates heterogeneity of SDOs governance architecture and institutional processes (Baron et al., 2019). Generally, a distinction can be made between four models of SDO governance in the ICT sector: national representation; balance of commercial interests; engineering societies (constituting "democracies of experts") and open, apolitical consortia. In reality, these models are often combined in SDOs' governance frameworks.

SDOs based on national representation are comprised of national committees established at the country level and according to the national rules. Examples of this model are the International Telecommunication Union (ITU), the International Organization for Standardization (ISO) and the International Electrotechnical Commission (IEC). Stakeholders can only participate in these SDOs by virtue of their membership in the national committees. The Assembly of national committees serves as the main governance body of these SDOs and is formally entrusted with the final standards approval. National committees participating in these interenational organizations are supposed to represent a national consensus, as opposed to an individual view or a specific stakeholder's interests. This type of SDOs, and their standards, are often recognized by governmental authorities and enjoy certain level of public law legitimacy (Baron et al., 2019).

The second governance model is rooted in the principle of direct representation of commercial stakeholders, and is illustrated by such global SDOs as 3GPP and OneM2M project. While their membership is open for different types of entities, including regulatory agencies and consumer associations, commercial companies usually prevail in the composition of these SDOs' membership. Most of the SDOs that are based on representation of stakeholders seek a balanced representation of different categories of commercial interests, and seek to avoid dominance by individual stakeholders.

SDOs designed according to the third governance model are associations of professionals, usually engineers. Traditionally, individuals are supposed to participate in these SDOs in their individual capacity and according to the norms of conduct of the profession. This governance model entails elements of a democratic process, seeking to give equal voice to all individual members. For instance, individuals holding the highest leadership positions in such SDOs are often appointed through general elections by the SDO's individual members. ${ }^{9}$. In practice, many of these SDOs feature both organizational and individual representation, and companies can seek membership and explicit representation. An example of such an SDO is the Standards Association of the Institute of the Electrical and Electronics Engineers (IEEE-SA).

\footnotetext{
${ }^{9}$ To enhance their legitimacy, such SDOs may seek formal accreditation of their processes or standards by an organization in the highest hierarchical positions, such as the American National Standards Institute (ANSI) ISO or the Joint Technical Committee 1 (JTC1), which transposes public law requirements imposed on these national and global standards bodies to private-sector associations
} 
The fourth model is centred on individual participation and represents "informal groups of likeminded experts:" IETF, which started as a loosely organized group of Internet researchers and to this day operates without formal membership requirements, is a vivid example of this governance model. Although some consortia have pledged the alignment of their processes with public law principles for standardization governance ${ }^{10}$, they do not explicitly seek government recognition or accreditation from formal accreditation bodies.

More generally, a distinction can be made between two different approaches to SDO participation. Under the entity-based approach, epitomised by the first two governance models, standardization decisions should reflect consensus of all relevant stakeholders and assure sufficient representation of different types of (commercial) interests. Under the individual-based approach, which is characteristic of the third and fourth governance model, standardization decisions should reflect a technical consensus among subject matter experts, and SDOs operating under this approach seek to be open to any interested individual expert. Such SDOs sometimes actively discourage individuals to represent the interests of their employer or affiliation, and view the ability of individual participants to disscociate themselves from the interests of their employer as vital to the independence of the SDO.

Next to a set of formal rules that define SDOs' membership, voting rights and obligations of SDO participants, the conduct of business within SDO committees hinges upon informal practices and expectations rooted in cultural historical traditions, which determine the hierarchy of operational rules and their interpretation. Moreover, SDOs are usually comprised of many committees, which in turn are made up of specialized groups, each of these sub-committees having their long-established practices and customs. The following section explains how the leadership of these working and subcommittees is elected in the different types of SDOs.

\subsection{Leadership selection}

Each SDO has its own rules for election or appointment of its leadership that are entrenched in historical traditions and have evolved due to the membership expansion and emerging jurisprudence. In theory, holding a chair position in a working group does not provide individuals with any influence over standards development. In practice, however, even if the precise description of their tasks and responsibilities may slightly differ per SDO, chairs usually have considerable power in standardization decisions: they coordinate the activities of their working group, serve as the first stage of appeal of a wroking group's decision and determine whether consensus has been achieved. Furthermore, a decision or action of a working group chair may be attributable to the SDO and lead to its antitrust liability ${ }^{11}$.

\footnotetext{
${ }^{10}$ E.g. IAB reply to the European ICT questionnaire, 'Impact assessment study on the "standardization package." Request for information from forums and consortiums' at https://www.iab.org/wpcontent/IAB-uploads/2011/03/2010-02-05-IAB-Response-Euro-ICT-Questionnaire.pdf

${ }^{11}$ American Society of Mechanical Engineers v. Hydrolevel Corporation, 456 U.S. 556 [1982] para 43
} 
3GPP and OneM2M Working Group officials are elected by the members of the respective Working Group every two years. ${ }^{12}$ Candidates for (vice)-chairmanship should provide a letter of support from the 3GPP/OneM2M Member, which should also assure that the candidate's compliance with antitrust rules if elected for the office. ${ }^{13}$. To maintain the balance in leadership, 3GPP's Working Group's chair and vice-chair, as well as their successive officials, cannot be from the same region, organizations partner or group of companies, unless no other individual is available to hold the office. ${ }^{14}$. A similar requirement to endeavor regional balance applies for OneM2M leadership elections. ${ }^{15}$ If there are multiple candidates nominated for the chair position, the election of Working Groups' officials occurs through secret balloting, with a threshold of $71 \%$ of Working Groups members voting and present; if the processes is unsuccessful, it is followed by a second ballot between the candidates obtaining highest amount of votes. ${ }^{16}$ Individuals can be re-elected as Working Group chairs or vice-chairs for the second term, and exceptionally, their tenure in the office can last even longer; however, there are no restrictions for chairs whose tenure is due to expire to volunteer for vice-chair election and vice-versa. ${ }^{17}$ An incumbent chairman or vice chairman who changes their affiliation is required to present a new letter of support from their new employer. If affiliation is changed due the individual's hire by another company, and not their company's merger or acquisition, the Working Group should also agree by consensus that the individual can remain in their role as a (vice-) chair. ${ }^{18}$

IEEE-SA Working Groups chairs are either appointed by a standards committee or elected by the respective Working Group. ${ }^{19}$ Procedures for officials' election, as well as the definition of what constitutes consensus, are further specified in the Working Group's charters; when establishing these procedures, Working Groups may deviate from the IEEE-SA Baseline procedures, but their requirements have to be followed when assigning tasks and responsibilities the elected individual. IEEE-SA 802.11 working group chairs are elected bi-anually from the nominated individuals, following a debate in the working group, upon receiving a simple majority of cast votes ${ }^{20}$. While there is no specification of the qualities and skills crucial for the candidates, it is required that the Working Groups' chairs hold the membership of both IEEE and IEEE-SA, which implies that by the virtue of individual IEEE membership, they should be familiar to and with the SDO. There is no

\footnotetext{
123GPP Working Procedures, September 30, 2020, Art.22. OneM2M Working Procedures - V8.0, June 11, 2019, Art. 14

${ }^{13} 3$ GPP Working Procedures, September 30, 2020, Art.22.1 and OneM2M Working Procedures - V8.0, June 11, 2019, Art. 14(a), which by analogy apply to working group leadership

${ }^{14} 3$ GPP Working Procedures, September 30, 2020, Art.22.1, which by analogy applies to working group leadership

${ }^{15}$ OneM2M Working Procedures - V8.0, June 11, 2019, Art. 14(a)

${ }^{16} 3$ GPP Working Procedures, September 30, 2020, Art. 28. OneM2M Working Procedures - V8.0, June 11, 2019, Art. 20

${ }^{17}$ GGPP Working Procedures, September 30, 2020, Art. 22.1. OneM2M Working Procedures - V8.0, June 11, 2019, Art. 14(a)

${ }^{18} 3$ GPP Working Procedures, September 30, 2020, Art. 22.1. OneM2M Working Procedures - V8.0, June 11, 2019, Art. 14(a)

${ }^{19}$ How are Working Groups Governed? https://standards.ieee.org/develop/mobilizing-workinggroup/governedwg.html

${ }^{20}$ IEEE 802.11 Wireless Local Area Networks Operations Manual, 13 July 2018, Art. 3.4
} 
overarching requirement for a maximum term of office: chairs may either serve limited terms or undergo a regular vote confirmation. ${ }^{21}$

IETF Working Group chairs are assigned by the Area Directors who in turn are selected by a nomination committee (NomCom). NomCom members are randomly selected from a pool of volunteers and approved by the Internet Architecture Board (IAB). ${ }^{22}$ While both technical and communication skills of a chair candidate matter, individuals who have been around in IETF for a long time and have been actively participating in its meetings are more likely to get appointed as chairs, especially if they gained "favorable prominence" by having previously contributed to the documents or volunteered to review them. ${ }^{23}$ IETF chairs have a wide discretion in administering Working Group activities and may also take decisions on behalf of their Working Group. They are expected to balance "progress and fairness" and ensure that the Working Groups move forward while the process remains fair and open. ${ }^{24}$

\subsection{Behavior expectations of SDO leadership}

The role of leadership is critical in a highly competitive environment of ICT standardization: experts sitting on the committees may wear different hats and have contradictory commitments to their employer, peers or profession. Although it remains challenging to determine experts' motives to take part in standardization processes, the individual dimension of standardization is crucial to understanding the dynamics within SDOs' committees and how the SDO governance rules shape companies' strategies to acquire leadership positions. Some theoretical observations can already be drawn from the comparative analysis of the SDOs' formal rules for leadership appointment.

In SDOs following individual-based approach, such as IEEE and IETF, chairs appear to have a more critical role for not only safeguarding, but also defiing balance and fairness between different stakeholder interests in their working groups, since, unlike entity-based SDOs like 3GPP, there are no explicit requirements for commercial or geograhical balance. The maximum terms of chair appointments in 3GPP and OneM2M, two entity-based SDOs, as well as the requirement of the working group to re-state its support to the official who changed their affiliation, also illustrate the importance of preserving commercial and geographical balance in these organizations. In turn, there are no limitations for the IEEE-SA and IETF's officials' terms of office or changes of affiliations; especially in the IETF, chairs appear to enjoy a great level of trust to act in the interest of the SDO rather than their employer, unless internal investigations have proven otherwise, ${ }^{25}$

\footnotetext{
${ }^{21}$ How are Working Groups Governed? https://standards.ieee.org/develop/mobilizing-workinggroup/governedwg.html

${ }^{22} \mathrm{BCP}$ 25, IETF Working Group Guidelines and Procedures, September 1998, https://tools.ietf.org/html/bcp25

${ }^{23}$ RFC 4144, How to Gain Prominence and Influence in Standards Organizations, https://tools.ietf.org/html/rfc4144

${ }^{24}$ The Tao of IETF, November 8, 2018, https://www.ietf.org/about/participate/tao/, Art. 4.1

${ }^{25}$ Impartiality and neutrality of IETF chairs have been challenged on a number of occasions, but neither IESG nir UAB, the IETF's appeal bodies, did not find any evidence of conflict of interests stemming from the chairs' affiliation. See e-mail exchange titled "Continued Buse of Process by IPR-WG Chair", December 26, 2007 https://www6.ietf.org/iesg/appeal/anderson-2007-12-26.txt
} 
All SDOs commonly expect their official to act according to the highest standards of integrity. Since chairing a working group necessiates knowledge of and experience within in the SDOs' processes as well as specialized technical knowledge on the subject matter, it can be assumed that individuals selected or appointed into the roles of the chairs enjoy certain recognition by their peers as authoritative figures in their field of expertise. Next to this professional expertise, neutrality and impartiality are the main requirement for chairs in all four SDOs analyzed in this section.

\section{Empirical analysis}

\subsection{Hypotheses}

Based on the limited available evidence on the patterns of participation of Huawei and Chinese individuals in SDOs, and our general understanding of the institutional features of the SDOs in our sample, we formulate a number of hypotheses to provide direction to the emprical analysis.

Hypothesis 1 (H1) Chinese (and other "Global South") nationals are under-represented in SDO leadership positions; but the extent of this under-representation erodes over time.

We hypothesize that there are three different potential mechanisms which combine to produce this result.

- "Mechanical" latency: Historically, the SDOs in our sample were dominated by Western nationals. As chairs are overwhelmingly selected among an SDO's attendees, new entrants enter as attendees, and can only rise to higher positions when there are vacancies and new chair appointments.

- Experience/human capital: Even when there are new appointments, individuals from China and the broader Global South may be less likely to be selected, because on average they have less experience within the SDO than their Western counterparts. Repeat attendance in an SDO significantly contributes to an individual's human capital (knowledge of the SDO's functioning and rules, knowledge of the standards under development) and social capital (reputation, trust, personal ties with other SDO participants), and increases the likelihood of being appointed to an SDO leadership position.

- Cultural incompatibility or bias: Chinese/Global South nationals may be more or less likely to be appointed then attendees from Western countries with similar levels of experience. On one hand, individuals from the Global South may be more likely to be appointed than similarly experienced Western attendees in SDOs that have an incentive to seek a greater geographical balance in their leadership. On the other hand, there may be cultural incompatibilities and language barriers, making Western nationals more likely to seek and be appointed to leadership positions in

and Appeal Against the Removal of the Co-chairs of the Geopriv Working Group, April 23, 2007 https://www6.ietf.org/iesg/appeal/gellens-2007-06-22.pdf 
organizations wiith a predominantly Western membership. Furthermore, as the majority of attendees and members are from Western countries, Western individuals may be more likely to be appointed because of homophily bias of the selectors.

In our empirical analysis, we will discuss the relative support of the evidence for each of the different mechanisms. We do not seek to formally identify a specific causal mechanism. In particular, we do not observe individuals who unsuccessfully seek to be appointed to chair positions, and unlike Baron et al. (2021b), we do not exploit exogeneous variation in the characteristics of selectors; and thus we cannot disentangle effects on individuals' motivation to be a candidate for a chair position from effects on individuals' chances of being selected if there are competing candidates.

Hypothesis 2 (H2) Affiliates of Huawei (and other competitors for global SDO leadership) are over-represented in SDO leadership positions.

We hypothesize that three different mechanisms could combine to produce this effect:

- SDO working group chairs are unpaid volunteers; i.e., they have to take time from their regular work, and are compensated by their employers to serve the SDO. Companies with significant stakes in standardization are more likely to be willing to incur the expense of "volunteering" their employees' time for SDO work.

- Individuals holding or susceptible of being appointed to leadership positions are more likely to be recruited by one of the companies competing for SDO leadership

- Companies with significant stakes in standardization decisions are likely to be willing to pay a premium for these individuals' SDO-specific social/human capital

- At equal pay, individuals with significant involvement in an SDO are likely to prefer working for a company willing to support their activities within the SDO; as stated above, this is more likely to be the case with companies with significant stakes in standardization.

- Other participants may be more or less likely to choose individuals affiliated with powerful stakeholders to SDO leadership positions

- On one hand, individuals affiliated with one of the companies competing for SDO leadership may be less likely to be chosen because of concerns over conflicts of interest, dominance, or potential hidden agendas. In light of the discussions cited in the introduction, these concerns are likely to be exacerbated with respect to Huawei in recent years.

- On the other hand, these individuals may be more likely to be chosen, because SDOs have incentives to choose representatives of powerful stakeholders. In particular, allowing leading companies to be represented provides incentives for these companies to contribute to standardization and increases the chances of the standards' success in the market. Also, given that individuals affiliated with such companies are more likely to benefit from the support of their employer for their SDO-related activities, they are less likely to face conflicts of commitment between their work as chair and their regular work duties. 
In our empirical analysis, we will identify and discuss the relative support for the different mechanisms. In particular, we wish to distinguish whether the affiliates of powerful stakeholders are more likely to be appointed to chair positions because of their superior individual experience and intrinsic capacities (as companies with significant stakes in standardization are more likely to recruit individuals with a capacity to influence standardization) or whether being affiliated with a powerful stakeholder increases the chances of being appointed to a leadership position for any given individual. If individuals owe their leading position in SDOs (and their influence over standardization decisions) to their affiliation, they are more easily replaceable, and have more limited bargaining power to resist demands by the company to execute an agenda that may potentially conflict with the interests of the SDO. If influence within the SDO however is a function of individual characteristics, companies with stakes in standardization must recruit experienced and respected members of an SDO's community; these individuals' values, concern for peer recognition, and incentives to preserve their individual social capital may act as a check on a company's attempt to influence standardization outcomes through employees holding SDO leadership positions.

First, we focus on recruitments of experienced individuals by Huawei and other companies competing for SDO leadership:

Hypothesis 3a (H3a) Huawei (and other companies competing for SDO leadership) are more likely to recruit individuals with SDO experience and/or holding SDO leadership positions.

Hypothesis $\mathbf{3 b} \mathbf{( H 3 b )}$ The difference may be more pronounced for SDOs with a model of individual participation, as opposed to direct representation of stakeholders.

- As a matter of formal SDO rules, the appointment to a leadership position is independent of an individual's affiliation. The appointment does not cease or must be renewed in the case of change of affiliation.

- More generally, we hypothesize that social capital associated to SDOs based on individual participationis more strongly vested with individuals than in entity-based SDOs such as 3GPP and OneM2M. ${ }^{26}$

Hypothesis 3c (H3c) Mobility to Huawei may be stronger or weaker than mobility to other top competitors for SDO leadership.

- On one hand, Huawei is susceptible of paying the largest premiums for individuals with SDO experience, as it has significant stakes in standardization outcomes, and still has to catch up with leading competitors in terms of SDO-specific human and social capital.

- On the other hand, working for Huawei may not be most conducive to individuals' career aspirations within SDOs; as other participants' concerns over potential conflicts of interests may be exacerbated.

\footnotetext{
${ }^{26}$ In SDOs based on direct stakeholder representation, the predominant form of social capital (e.g. trust) may be built through repeated interaction between different companies/organizations (Larouche and Schuett, 2019).
} 
Second, we analyze the effect of affiliation with a leading competitor for SDO leadership on a given individual's likelihood of being appointed to a chair position:

Hypothesis 4a (H4a) Affiliation with a leading competitor for SDO leadership increases the likelihood of an individual to be appointed chair.

- see H2 above, and in particular mechanisms 1 and 3

Hypothesis $\mathbf{4 b} \mathbf{b} \mathbf{H} \mathbf{b})$ This effect may be stronger or weaker for Huawei as compared to other top competitors for SDO leadership

- Huawei may be particularly encouraging of individuals' aspirations to seek leadership positions in the SDO.

- If an individual is a candidate for a chair position, the effect of being affiliated with Huawei on the chances of being appointed may be negative because of concerns over conflicts of interests.

Hypothesis 4c (H4c) Effect may be stronger at IETF than 3GPP, IEEE, and OneM2M

- The willingness of the company to support SDO work may be higher at IETF, 3GPP, and OneM2M than at IEEE (which particularly discourages representation of companies' interests)

- Reluctance to appointing affiliates of a leading affiliation may be lower at IETF than $3 \mathrm{GPP}$ and OneM2M. As a consequence of IETF's "culture of meritocracy", there is lower emphasis on balancing the representation of different interests (part of the "politics" traditionally shunned by IETF). ${ }^{27}$

\subsection{Data and methodology}

\subsubsection{Data on attendees and chairs}

We collected meeting attendance and working group chair information from the websites of 3GPP, IEEE SA, IETF, and OneM2M. After collecting raw names from the SDOs' attendance records, we standardized the individual attendee and chair names, using additional information such as affiliation, contact information, and working group name, for disambiguation. Similarly, we collect affiliation information from the SDO attendance records. In some cases, we use the domain of the e-mail address to identify the affiliation. ${ }^{28}$ Individuals may provide different affiliations, such as their employer or a membership organization in which they are member. We attempt to identify the primary affiliation, which we consider to be the most likely primary employer of the individual. We thus give

\footnotetext{
${ }^{27}$ Baron et al. (2021a) e.g. describe how IETF has consistently resisted implementing balance of interests requirements.

${ }^{28}$ Attendance records of 3GPP, IEEE-SA 802.11, and OneM2M list affiliations of attendees. At IETF, information on affiliation varies between meetings; if no affiliation information is provided, we use the domain names of e-mail addresses, or interpolate affiliation (if an individual has attended an earlier and later meeting with the same affiliation information, we assume that this was the affiliation at the meeting for which affiliation information is missing). In total, we observe affiliation for 94,722 , or $87.5 \%$, of the IETF attendance observations.)
} 
priority to company or government authority affiliations over membership organizations. The steps for the standardization of individual and firm names are explained in greater detail in Baron (2020).

In the case of companies, we standardize this affiliation information to the level of the global ultimate owner (GUO). ${ }^{29}$ Standardization of firm names to the GUO level is dynamic; in particular, we use hand-collected information on 262 mergers, acquisitions, and spinoffs to standardize GUO information over time. ${ }^{30}$ We also use this information to distinguish between "recruitments" and changes of affiliation due to changes in corporate structure. $^{31}$

In the case of $3 \mathrm{GPP}$ and OneM2M, we retrieved attendance records of working group meetings. The data includes the meeting reports of the meetings of six 3GPP TSG as well as their 31 working groups; and ten different working groups of OneM2M. In the case of IETF, we collected attendance records from 75 IETF meetings from 1994 to 2019, inclusive. IETF working groups meet during the general IETF meetings. While in some cases there is attendance data for individual working group meetings, this information is not sufficiently systematically available. Nevertheless, IETF meeting attendance is a condition for working group meeting attendance. At IEEE-SA, we only have data on attendance in a single working group, 802.11. In total, we thus collected 340,250 attendance records from 3,381 different meetings, with information on 45,253 different individuals and 7,930 different affiliations.

Similarly, we collect data on working group chair names. In the case of $3 \mathrm{GPP}$ and OneM2M, meeting reports indicate the role of each individual attendee. In addition to "attendee" or "delegate", possible roles include "chair", "vice-chair", "secretary", and "rapporteur". In the case of IETF and IEEE-SA 802.11, we hand-collected chair and vice-chair observations ffrom the minutes of each working group meeting. Overall, we

\footnotetext{
${ }^{29}$ Standardization of affiliations at the GUO level reflects the standard assumption in economic research that firm conduct is determined at the GUO level. This assumption may be challenged, in particular with respect to Huawei-owned Western companies such as Futurewei. US restrictions against Huawei, which do not apply to US companies such as Futurewei, have barred Futurewei employees from exchanging technical information with the parent company and have led Futurewei affiliates to distantiate themselves from Huawei. The restrictive policies may also have created limitations for Huawei's effective control over the conduct of Futurewei employees. Nevertheless, this generally occurred after our observation period. Prior to 2019, even Futurewei employees themselves generally self-identified as affiliates of Huawei; see https://www.ft.com/content/76f50b38-d32d-11e9-a0bd-ab8ec6435630

${ }^{30}$ Not-fully owned companies, incl. joint ventures such as Nokia Siemens Networks (prior to full acquisition by Nokia) and Convida Wireless, are treated as independent GUOs. However, changes of affiliations between such entities and one of their parents are not treated as recruitments. Observations with such "internal" changes of affiliation are censored, i.e. treated as neither change of affiliation nor continuation with the same affiliation.

${ }^{31}$ In the case of mergers and acquisitions, we observe a change of affiliation at the date of the M\&A event, regardless of whether the affiliation of the individual in attendance records continues to be the name of the acquired entity or changes to the name of the new parent company. For spinoffs and transfers of companies from one parent to another (e.g. Motorola Mobility acquired by Lenovo from Google), we observe changes of affiliation for those individuals who continuously list the company that was transferred as their affiliation; or if we observe a change in affiliation between the former and the new parent that coincides with the date of the event (e.g. an attendee changing affiliation from Google to Lenovo concurrently with Motorola Mobility's acquisition by Lenovo is identified as having changed affiliation due to a change in corporate structure; whereas a change of affiliation between these two companies in another year would have been classified as recruitment).
} 
collected 19,194 chair observations from 10,048 meetings; with 1,377 different individuals serving as chair, and 2,627 different chair positions being filled.

\begin{tabular}{l|ccccc}
\hline \hline & 3GPP & IEEE-SA & IETF & OneM2M & Total \\
\hline Attendance & & & & & \\
Meetings & 2,712 & 66 & 75 & 520 & 3,367 \\
Attendance records & 202,451 & 15,595 & 108,234 & 13,970 & 325,371 \\
Individual attendees & 14,459 & 1,986 & 30,406 & 1,029 & 40,672 \\
Different affiliations & 986 & 577 & 7,236 & 214 & 6,466 \\
\hline Chairs & & & & & \\
Meetings & 2,353 & 62 & 6,211 & 754 & 9,380 \\
Chair observations & 7,476 & 516 & 11,546 & 763 & 20,301 \\
Chair persons & 517 & 63 & 871 & 34 & 1,474 \\
\hline Observation period & $1999-2019$ & $2007-2017$ & $1994-2019$ & $2012-2019$ & $1994-2019$ \\
\hline \hline
\end{tabular}

Table 1: Descriptive statistics by type of standards organizations

\subsubsection{Independent variables}

For each of these individuals, we collected information on explanatory variables at the individual and affiliation level. We build several variables from our comprehensive SDO attendance data: seniority measures the time elapsed since the first meeting attendance, and attendance measures the number of meetings attended (in total, at individual SDOs, and in individual working groups). We don't observe working group attendance in IETF. Nevertheless, we are able to use additional measure of participation in IETF; notably the cumulative number of authorships of requests for comments, or RFC (RFC_author), and e-mail authorships in IETF mailing lists (Ganglmair et al., 2018). ${ }^{32}$ RFCs are the deliverables of IETF, including its standards and non-standard output (Simcoe, 2012). Unlike attendance or RFC authorship data, e-mails can be attributed to individual working groups. ${ }^{33}$

For a general measure of relevant technical expertise, we collect information on patent inventorship in the related technical field. In order to make patent counts comparable accross different World regions, and to account for heterogeneity in patent value, we count triadic patent families, or TPF. ${ }^{34}$ We count the cumulative number of TPF by inventor over time, by date of first application (number_patents). The count is limited to the 20 International Patent Classification (IPC) classes most relevant to the standards of the SDOs in our sample ${ }^{35}$ We also count the number of TPF for which at least one member

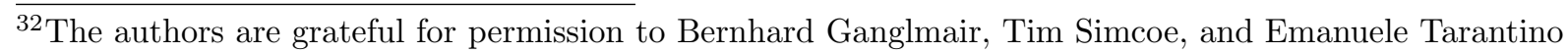
for permission to use this data.

${ }^{33}$ The matching between IETF mailling lists and working groups results from the research for Baron et al. (2021b).

${ }^{34}$ These are inventions for which a patent was granted by at least the following three patent offices: the US Patent and Trademark Office (USPTO), the European Patent Office (EPO), and the Japanese Patent Office (JPO). TPF are generally considered to be patents of higher quality and higher value (see Sternitzke (2009) for a discussion). We use the OECD Database of TPF (Dernis and Khan, 2004).

${ }^{35}$ We matched the TPF patent numbers with the Searle Center data on declared SEP (Baron and Pohlmann, 2018), and identify the 20 IPC classes with most patents in TPF declared essential to these SDOs' standards.
} 
was declared essential to an SDO, by date of first declaration (number_sep) (using the SEP declaration data collected by Baron and Pohlmann (2018)). We count both total numbers of SEPs, and SEPs by SDO.

In addition, we produce information on attendees' likely country of residence. Many attendance records include phone, and sometimes fax numbers. We use the country code of the phone numbers to observe country of residence. Second, many IETF meeting attendance records include information on attendees' self-stated country. ${ }^{36}$ Third, in the case of patent inventors, the TPF patent database includes information on inventor country of residence. For each individual, we aggregate the different country-of-residence observations, and select the country with the highest number of observations to assign a time-invariant country observation. We aggregate country-of-residence information to six World "regions": Europe, North America, China, Japan, Korea, and the "Rest of the World".

At the affiliation level, we hypothesize that the type of organization, as well as the extent of the organization's involvement in the working group, the SDO, and in ICT standardization in general play an important role in determining the likelihood that their employees are appointed to chair positions. We categorize affiliations by the following types: company, university, public administration (including military, but excluding public research institutes), public research institutes, membership organizations, and other (or unknown). Among companies, we further distinguish between telecommunications network operators and all other companies. We classify the affiliations accounting for the largest number of attendance records by hand. For the remainder, we use detailed regular expression searches; supported by manual classification (see Baron (2020) for details). Using total attendance counts over the entire period, we identify the "Top 5" companies with the largest extent of participation in our four SDOs: Cisco, Ericsson, Huawei, Nokia, and Qualcomm (in alphabetical order). We refer to these companies as the "companies competing for SDO leadership". ${ }^{37}$

To measure the extent of involvement in the SDO, we count cumulative attendance in the SDO and in the working group at the affiliation level. ${ }^{38}$ We count current memberships in standards organizations as a measure of a firm's involvement in ICT standardization in general, using the Searle Center Database (Baron and Spulber, 2018). ${ }^{39}$ In addition, we use information on the number of declared SEP collected by Baron and Pohlmann $(2018) \cdot{ }^{40}$

\footnotetext{
${ }^{36}$ We do not know whether attendees receive additional guidance which country to provide, e.g. country of residence as opposed to country of citizenship.

${ }^{37}$ Alternatively, we also use the list of the "Top 20" affiliations, also including Alcatel-Lucent (prior to acquisition by Nokia), AT\&T, Blackberry, Deutsche Telekom, Fujitsu, Intel, LG Electronics, Motorola (prior to acquisition of Motorola Mobility by Google), NEC, NTT, Orange, Panasonic, Samsung, Vodafone, and ZTE.

${ }^{38}$ All cumulative counts at the affiliation level are transferred along with the firm in the case of M\&As, i.e. the acquired firm's stock is added to the stock of the acquiring parent company after the date of acquisition.

${ }^{39} \mathrm{To}$ account for observation gaps in the membership data, we interpolate the membership information.

${ }^{40}$ In light of the challenges with using patent counts discussed above, we match the information on declared SEP with the OECD TPF database; and only retain information on TPF with at least one member declared to be potentially essential.
} 

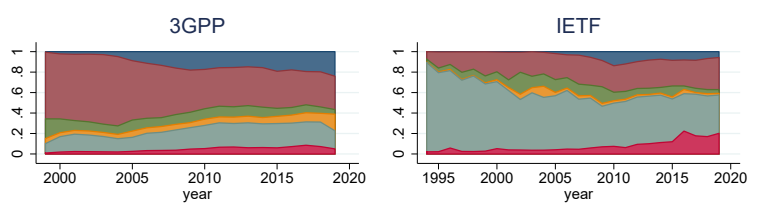

IEEE
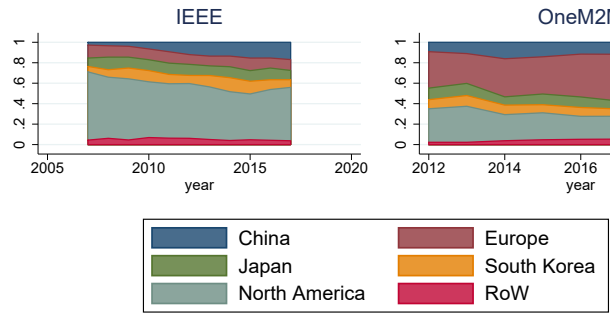

(a) Share of attendance counts
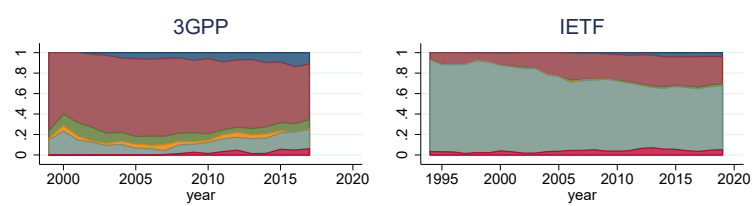

IEEE
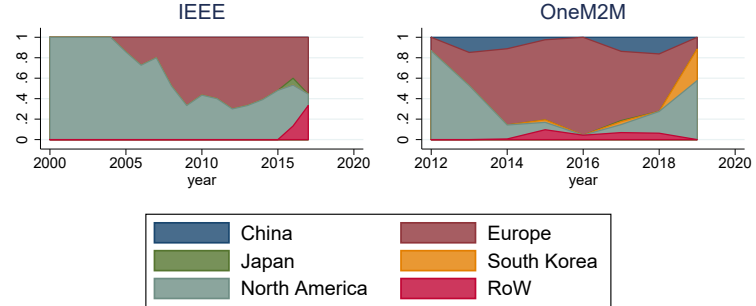

(b) Share of chair counts

Figure 1: Share of attendees and chairs, by region and over time

\subsection{Descriptive statistics}

\subsubsection{Evolution of attendance and chair patterns over time}

The attendance data that we collected reveals the rapid diversification of SDO participants over time. Historically, a large majority of 3GPP attendees came from Europe, whereas the vast majority of attendees at IEEE-SA 802.11 and IETF came from North America (Figure 1a). This pattern has changed significantly, however, in particular due to the rising role of participation from China and the "Rest of the World" (predominantly other countries of the 'Global South', such as India). Only OneM2M has witnessed a slight decrease in the geographical balance among its attendees, but the organization is also much younger. There is, however, significantly less geographical balance in SDOs' working group chair positions (Figure 1b). Europeans have consistently dominated chair positions at $3 \mathrm{GPP}$, while the large majority of chair positions at IETF continue to be held by North Americans. While this imbalance has decreased over time, especially at IETF, this is primarily due to a rising share of European chairs. Representation of China or the "Rest of the World" in chair positions significantly trails the share of these World regions among attendees.

These findings contrast with the rising role of Huawei, including in SDO chair positions (Figure 2). Attendance by Huawei affiliates has increased dramatically over a relatively short period of time (and only decreases in 2019 due to attrition in the data). In the four most recent years, Huawei was the affiliation with the largest number of attendees in each of the four SDOs in our sample (the first time that a single organization has been leading attendance counts at all SDOs simultaenously). Huawei has also acquired a significant number of working group chair positions, even though this evolution has been less pronounced, and even as of the most recent years in the observation period, Huawei was not the largest affiliation of SDO chairs in any of the four SDOs.

\subsubsection{Characteristics of attendees and chairs}

Focusing only on the most recent years for which we have complete attendance data from all SDOs (2014-2017), we can describe the characteristics of SDO attendees and chairs. Table 

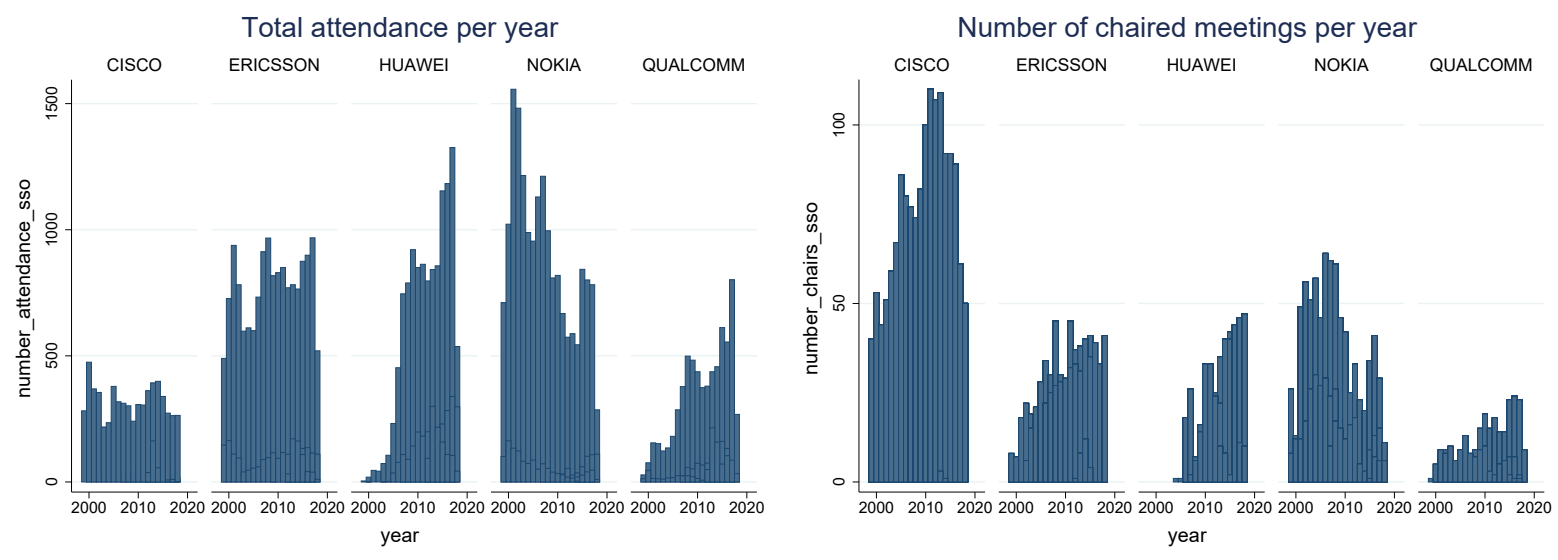

Figure 2: Yearly attendance counts and chair counts (number of chaired meetings) by GUO; all four SDOs

7 in Appendix A.1 compares the characteristics of attendees and chairs of the four SDOs. The tables confirm that Chinese continue to be under-represented in chair positions in every SDO, and that the difference between the share of Chinese among attendees and chairs is consistently statistically significant. Affiliates of Huawei, however, are over-represented in chair positions at both 3GPP and IETF; in fact, in both SDOs, a larger number of chair positions is held by Huawei affiliates than by all Chinese nationals (reflecting the significant role of Western nationals affiliated with Huawei). Over-representation in chair positions is typical of all companies competing for SDO leadership, however, and the extent of Huawei's over-representation is actually smaller than the one observed for Top 5 or Top 20 affiliations in general. Affiliations of chairs are thus generally less diverse than affiliations of attendees; at 3GPP, an impressive $82 \%$ of the chair positions were held by one of the Top 20 companies.

Chairs at 3GPP also tend to be affiliated with companies (or other organizations) that are generally more involved in standardization. For instance, on average, approx. 100 other individuals affiliated with the chair's affiliation had previously attended a 3GPP meeting (as compared to 66.5 other individuals also affiliated with the affiliation of meeting attendees); and chairs' affiliations were member of an average of 40 standards organizations (as compared to 30 for attendees). ${ }^{41}$ The latter difference between chairs and attendees also exists at IEEE-SA 802.11 and IETF, but chairs' affiliations are not generally represented by a larger number of individuals within these SDOs than the affiliations of attendees.

Unsurprisingly, in all four SDOs, chairs have significantly more SDO experience than attendees, both in terms of number of meetings previously attended, and seniority (time elapsed since firts participation in the SDO). At 3GPP, chairs are also significantly more prolific inventors of patents than attendees, including but not limited to declared SEPs. As the signficant difference in seniority suggests that chairs are older on average than attendees, we also compare patent inventorship over the last four years preceding each meeting, and find similarly significant differences. This difference is however unique to

\footnotetext{
${ }^{41}$ The count refers to standards organizations included in the Searle Center Database, see Baron and Spulber (2018).
} 
3GPP; chairs are generally less prolific inventors of patents than attendees at other SDOs (and the average number of patents per attendee or chair is also much lower than at 3GPP).

\subsubsection{Characteristics of the affiliates of Huawei and other companies competing for SDO leadership}

In all SDOs, there are significant differences in the characteristics of individuals affiliated with one of the five top competitors for SDO leadership and other organizations (Table 8, Appendix A.1). Individual affiliates of these organizations have significantly more SDO experience than other individual attendees, and they are generally much more prolific patent inventors. These differences surely contribute to explain the outsized representation of these companies in SDO leadership positions. The descriptive statistics however do not allow disentangling whether these differences are due to intrinsic characteristics of individuals (i.e. companies with significant participation in standardization are more likely to recruit individuals with SDO experience and a track record of inventorship in the field), or whether being affiliated with one of these companies allows (or incentivizes) individuals to attend a larger number of meetings and file for a larger number of patents. We will partly disentangle these effects in the remainder of the analysis.

Table 9 presents differences between affiliates of Huawei and other Top 5 affiliations. Especially at 3GPP, affiliates of Huawei have significantly less SDO experience than the affiliates of Huawei's competitors for SDO leadership. These differences reflect the later entry of Huawei in the competition, and may contribute to explain why Huawei's leading position among attendees has not translated into an even larger number of chair positions. We expect that over the observatin period Huawei attempted to "catch up" and reduce this experience gap with its leading Western competitors. One potential strategy, which we will analyze in Section 4.5, consists in recruiting experienced SDO participants. Another strategy is already apparent from Table 9: particularly assiduous attendance. While Huawei affiliates have several years less SDO experience than affiliates of Huawei's leading Western competitors, they have already caught up in terms of number of attended meetings in all SDOs but 3GPP. This pattern of particuarly intensive attendance, however, also affects the average quality of attendees. While their relative lack in SDO experience may be attributed to Huawei's later entry, attendees affiliated with Huawei (at all SDOs except at IETF) are also characterized by significantly lower numbers of patent inventorships (TPF) (including patents with priority date in the four years preceding the meeting) than is typical of affiliates of the main competitors for SDO leadership.

\subsection{Regression analysis: who becomes a chair?}

The descriptive results already provide ample evidence that is consistent with Hypotheses 1 and 2. Nevertheless, the results give little indication of the reasons for the underrepresentation of Chinese nationals in chair positions, or the over-representation of large companies, including Huawei. In particular, we expect that potential causes for overrepresentation of Western nationals may include "mechanical latency", gaps in SDO experience and proven expertise in the field, and persistent over-selection of Western individuals 
for reasons including cultural affinity, homophily, and outright discrimination (potentially motivated by concerns over undue influence by governmental or non-governmental entities).

As a first step to disentangle these different mechanisms, we conduct a conditional logit regression analysis of chair appointments. The overwhelming majority of new working group chairs are drawn from the working group's past attendees. In our conditional logit analysis, we thus identify for each new appointment the attendees of the working group's meetings of the preceding year, and analyze the factors determining which of these individuals is appointed to fill the chair position. ${ }^{42}$ Given the low number of new appointments at IEEE SA 802.11 and OneM2M over the observation period, we focus on $3 \mathrm{GPP}$ and IETF.

Unlike comparisons between current chairs and attendees, this analysis of new appointments of chairs is not subject to latency - if Chinese and other nationals of Global South countries are only under-represented in chair positions because they were not yet around when the current chairs were appointed, we would not expect Chinese attendees to be any less likely to be appointed to a new chair position than their Western counterparts. Appointments may also be influenced by SDO experience and other individual-level characteristics. While many of these characteristics are unobserved in our analysis, the regression framework and our comprehensive attendance database allow us to control for observable SDO experience.

\subsubsection{The role of nationality in chair appointments}

The results displayed in Table 2 reveal that when focusing on new appointments, and thus controlling for the latency effect, there is no significant (positive or negative) "China effect" in new appointments - as compared to the "Rest of the World". In comparison to Western nationals, Chinese are significantly less likely to be appointed to chair positions than Europeans at both $3 \mathrm{GPP}$ and IETF, and less likely to be appointed to positions at IETF than individuals from North America. Differences in observable SDO experience and proven expertise in the field - as measured by patent inventorship - accounts for a large share of this difference in the likelihood of appointment; nevertheless, the advantage of Europeans in both SDOs and of North Americans in IETF remains significant even when controlling for these observable characteristics (Models 3 and 7). This residual disadvantage of Chinese attendees with respect to their counterparts from Europe and North America has not changed significantly over time (Models 4 and 8).

While these results are generally consistent with a "home advantage" of Europeans in 3GPP and North Americans in IETF, they are not consistent with a persistent disadvantage for individuals from the "Global South". Controlling for observable experience and expertise, Chinese individuals are significantly more likely to be appointed to 3GPP chair positions than individuals from North America and Japan. At IETF, Japanese individuals are very significantly less likely to be appointed to chair positions not only than their Chinese counterparts, but also than similarly qualified individuals from the "Rest of the World" (a

\footnotetext{
${ }^{42}$ For IETF, we include all attendees of the IETF's general meetings of the preceding year - a substantially larger "risk set" including numerous irrelevant observations. By including e-mail contributions to working group-specific mailing lists, we are able to significantly improve the precision of our analysis of new chair appointments.
} 


\begin{tabular}{|c|c|c|c|c|c|c|c|c|}
\hline & \multicolumn{4}{|c|}{$3 \mathrm{GPP}$} & \multicolumn{4}{|c|}{ IETF } \\
\hline & (1) & $(2)$ & $(3)$ & $(4)$ & $(5)$ & $(6)$ & $(7)$ & $(8)$ \\
\hline europe & $\begin{array}{c}2.971^{* *} \\
(2.95)\end{array}$ & $\begin{array}{c}2.959^{* *} \\
(2.94)\end{array}$ & $\begin{array}{c}2.167^{*} \\
(2.13)\end{array}$ & & $\begin{array}{c}1.052^{* * *} \\
(4.84)\end{array}$ & $\begin{array}{c}1.051^{* * *} \\
(4.84)\end{array}$ & $\begin{array}{c}0.441^{*} \\
(2.01)\end{array}$ & $\begin{array}{l}0.441^{*} \\
(2.01)\end{array}$ \\
\hline northamerica & $\begin{array}{l}1.472 \\
(1.39)\end{array}$ & $\begin{array}{l}1.469 \\
(1.38)\end{array}$ & $\begin{array}{l}0.849 \\
(0.79)\end{array}$ & & $\begin{array}{c}1.354^{* * *} \\
(6.51)\end{array}$ & $\begin{array}{c}1.354^{* * *} \\
(6.50)\end{array}$ & $\begin{array}{l}0.536^{*} \\
(2.53)\end{array}$ & $\begin{array}{c}0.536^{*} \\
(2.53)\end{array}$ \\
\hline japan & $\begin{array}{l}1.658 \\
(1.51)\end{array}$ & $\begin{array}{l}1.647 \\
(1.50)\end{array}$ & $\begin{array}{l}0.965 \\
(0.87)\end{array}$ & & $\begin{array}{c}-1.246^{* *} \\
(-2.73)\end{array}$ & $\begin{array}{c}-1.247^{* *} \\
(-2.73)\end{array}$ & $\begin{array}{c}-1.677^{* * *} \\
(-3.67)\end{array}$ & $\begin{array}{c}-1.677^{* * *} \\
(-3.67)\end{array}$ \\
\hline china & $\begin{array}{l}1.776 \\
(1.66)\end{array}$ & $\begin{array}{l}-286.3 \\
(-1.28)\end{array}$ & $\begin{array}{c}2.148^{*} \\
(1.97)\end{array}$ & $\begin{array}{l}-307.0 \\
(-1.26)\end{array}$ & $\begin{array}{l}-0.286 \\
(-0.70)\end{array}$ & $\begin{array}{l}-54.06 \\
(-0.28)\end{array}$ & $\begin{array}{l}-0.384 \\
(-0.93)\end{array}$ & $\begin{array}{l}-42.86 \\
(-0.22)\end{array}$ \\
\hline china\#year & & $\begin{array}{l}0.143 \\
(1.28)\end{array}$ & & $\begin{array}{l}0.153 \\
(1.26)\end{array}$ & & $\begin{array}{c}0.0267 \\
(0.28)\end{array}$ & & $\begin{array}{c}0.0211 \\
(0.22)\end{array}$ \\
\hline attendance_wg_lasty & & & $\begin{array}{c}0.565^{* * *} \\
(8.89)\end{array}$ & $\begin{array}{c}0.574^{* * *} \\
(9.00)\end{array}$ & & & & \\
\hline attendance_wg_prior & & & $\begin{array}{c}0.0404^{* * *} \\
\quad(4.37)\end{array}$ & $\begin{array}{c}0.0412^{* * *} \\
\quad(4.45)\end{array}$ & & & & \\
\hline numbermails_wg_6m & & & & & & & $\begin{array}{c}0.00140^{* * *} \\
(7.14)\end{array}$ & $\begin{array}{c}0.00140^{* * *} \\
\quad(7.14)\end{array}$ \\
\hline number_rfcs & & & & & & & $\begin{array}{c}0.0118^{* * *} \\
(3.50)\end{array}$ & $\begin{array}{c}0.0118^{* * *} \\
(3.50)\end{array}$ \\
\hline attendance_plen_lasty & & & $\begin{array}{c}0.575^{* * *} \\
(6.79)\end{array}$ & $\begin{array}{c}0.568^{* * *} \\
(6.75)\end{array}$ & & & $\begin{array}{c}1.069^{* * *} \\
(17.34)\end{array}$ & $\begin{array}{c}1.069^{* * *} \\
(17.34)\end{array}$ \\
\hline attendance_plen_prior & & & $\begin{array}{c}-0.0248 \\
(-1.60)\end{array}$ & $\begin{array}{c}-0.0305^{*} \\
(-2.00)\end{array}$ & & & $\begin{array}{c}0.0213^{* *} \\
(2.90)\end{array}$ & $\begin{array}{c}0.0213^{* *} \\
(2.90)\end{array}$ \\
\hline seniority_sso & & & $\begin{array}{c}0.0000188 \\
(0.14)\end{array}$ & $\begin{array}{c}0.000107 \\
(0.82)\end{array}$ & & & $\begin{array}{c}-0.0000131 \\
(-0.27)\end{array}$ & $\begin{array}{c}-0.0000130 \\
\quad(-0.27)\end{array}$ \\
\hline \#patents_field & & & $\begin{array}{c}0.00677^{* *} \\
(3.10)\end{array}$ & $\begin{array}{c}0.00498^{*} \\
(2.32)\end{array}$ & & & $\begin{array}{c}-0.0353 \\
(-1.83)\end{array}$ & $\begin{array}{c}-0.0354 \\
(-1.83)\end{array}$ \\
\hline sep_inventor & & & $\begin{array}{l}-0.121 \\
(-0.47)\end{array}$ & $\begin{array}{c}-0.0899 \\
(-0.36)\end{array}$ & & & $\begin{array}{c}0.0164 \\
(0.08)\end{array}$ & $\begin{array}{c}0.0172 \\
(0.08)\end{array}$ \\
\hline company & & & $\begin{array}{l}1.198 \\
(1.83)\end{array}$ & $\begin{array}{l}1.101 \\
(1.72)\end{array}$ & & & $\begin{array}{c}0.320^{* *} \\
(2.63)\end{array}$ & $\begin{array}{c}0.320^{* *} \\
(2.63)\end{array}$ \\
\hline networkprovider & & & $\begin{array}{c}-0.0246 \\
(-0.08)\end{array}$ & & & & $\begin{array}{c}-0.421^{*} \\
(-2.22)\end{array}$ & $\begin{array}{c}-0.421^{*} \\
(-2.22)\end{array}$ \\
\hline university & & & $\begin{array}{l}-6.402 \\
(-0.01)\end{array}$ & $\begin{array}{l}-7.154 \\
(-0.01)\end{array}$ & & & $\begin{array}{c}0.0319 \\
(0.18)\end{array}$ & $\begin{array}{c}0.0318 \\
(0.18)\end{array}$ \\
\hline decl_sep_tpf_cumul_tot & & & $\begin{array}{c}0.000215 \\
\quad(0.36)\end{array}$ & $\begin{array}{c}0.000591 \\
(1.03)\end{array}$ & & & $\begin{array}{c}0.000437 \\
(1.27)\end{array}$ & $\begin{array}{c}0.000436 \\
(1.27)\end{array}$ \\
\hline sso_membership_count & & & $\begin{array}{c}0.0101 \\
(1.04)\end{array}$ & $\begin{array}{c}0.00284 \\
(0.32)\end{array}$ & & & $\begin{array}{c}0.00126 \\
(0.34)\end{array}$ & $\begin{array}{c}0.00128 \\
(0.35)\end{array}$ \\
\hline \#other_attendees_guo & & & $\begin{array}{c}0.0591 \\
(1.75)\end{array}$ & $\begin{array}{c}0.0800^{*} \\
(2.45)\end{array}$ & & & $\begin{array}{c}-0.00254 \\
(-1.54)\end{array}$ & $\begin{array}{c}-0.00256 \\
(-1.55)\end{array}$ \\
\hline$N$ & 36,860 & 36,860 & 36,860 & 36,860 & $1,292,933$ & $1,292,933$ & $1,292,933$ & $1,292,933$ \\
\hline Groups (appointments) & 109 & 109 & 109 & 109 & 584 & 584 & 584 & 584 \\
\hline
\end{tabular}

$t$ statistics in parentheses

${ }^{*} p<0.05,{ }^{* *} p<0.01,{ }^{* * *} p<0.001$

Table 2: Conditional logit regression analysis: who is appointed to become working group chair - Chinese v. other nationals 
collection of mostly developing countries). While the results clearly indicate that national origins matter for ascension to leadership positions within SDOs, they do not appear to matter for the reasons most frequently invoked - i.e. structural disadvantages for individuals from developing countries, and concerns over political interference affecting appointments of individuals from centralized economic systems with significant government control of standardization.

\subsubsection{The role of affiliations in chair appointments}

Next, we examine the role of affiliation with Huawei or another leading competitor for SDO leadership. The results are presented in Table 3. Not controlling for characteristics of the individual or general characteristics of the affiliation, affiliates of the "Top" companies competing for SDO leadership are signifcantly more likely to be appointed to working group chair positions than attendees with other affiliations (Models 1 and 5). Affiliates of Top 5 companies are significantly more likely to be appointed than affiliates of other Top 20 companies at both 3GPP and IETF; at 3GPP, affiliates of Top 20 companies are furthermore more likely to be appointed than other attendees (at IETF, it is only affiliates of Top 5 companies that are more likely to be appointed than other attendees). Huawei affiliates, however, are not significantly more or less likely to be appointed than affiliates of other leading companies (they are, however, significantly more likely to be appointed than the general population of attendees at 3GPP). There is no evidence that the appointment chances of Huawei affiliates with respect to Huawei's leading competitors have changed significantly over time (Models 2 and 6).

To a large extent, the differences between affiliates of top affiliations and the general population of attendees can be attributed to differences in individuals' characteristics. Controlling for past SDO experience and technical expertise in the field (as measured by patent inventorship), the chances of appointment become more similar between affiliates of top affiliations and other attendees, but the advantage of affiliates of large companies does not vanish entirely (Models 3 and 7 ). At 3GPP, these remaining differences may be fully explained by general characteristics of the affiliation, such as number of affiliates having participated in the SDO, and other measures of the extent of the affiliation's involvement in standardization (Model 4). At IETF, there continues to be a significant residual advantage of affiliates of the top 5 leading affiliations, which is robust to linear controls for standardization involvement (Model 8). This suggests that the likelihood of appointments to leadership positions does not increase linearly in the extent of an organization's involvement in standardization; rather, greater likelihood of ascending to leadership positions is specifically associated wit a very small number of affiliations competing for leadership.

Controlling for individual- or affiliation-level characteristics has no effect on the comparison between Huawei and its leading competitors. If anything, Huawei affiliates are less likely to be appointed to SDO leadership positions at IETF (mildly significant at $10 \%$ ) than similarly qualified attendees affiliated with other large organizations (and not significantly more or less likely than similarly qualified individuals in the general population of attendees).

While affiliation-level characteristics thus correlate with the likelihood of being appointed to working group chair positions, a much larger share of the variation is explained 


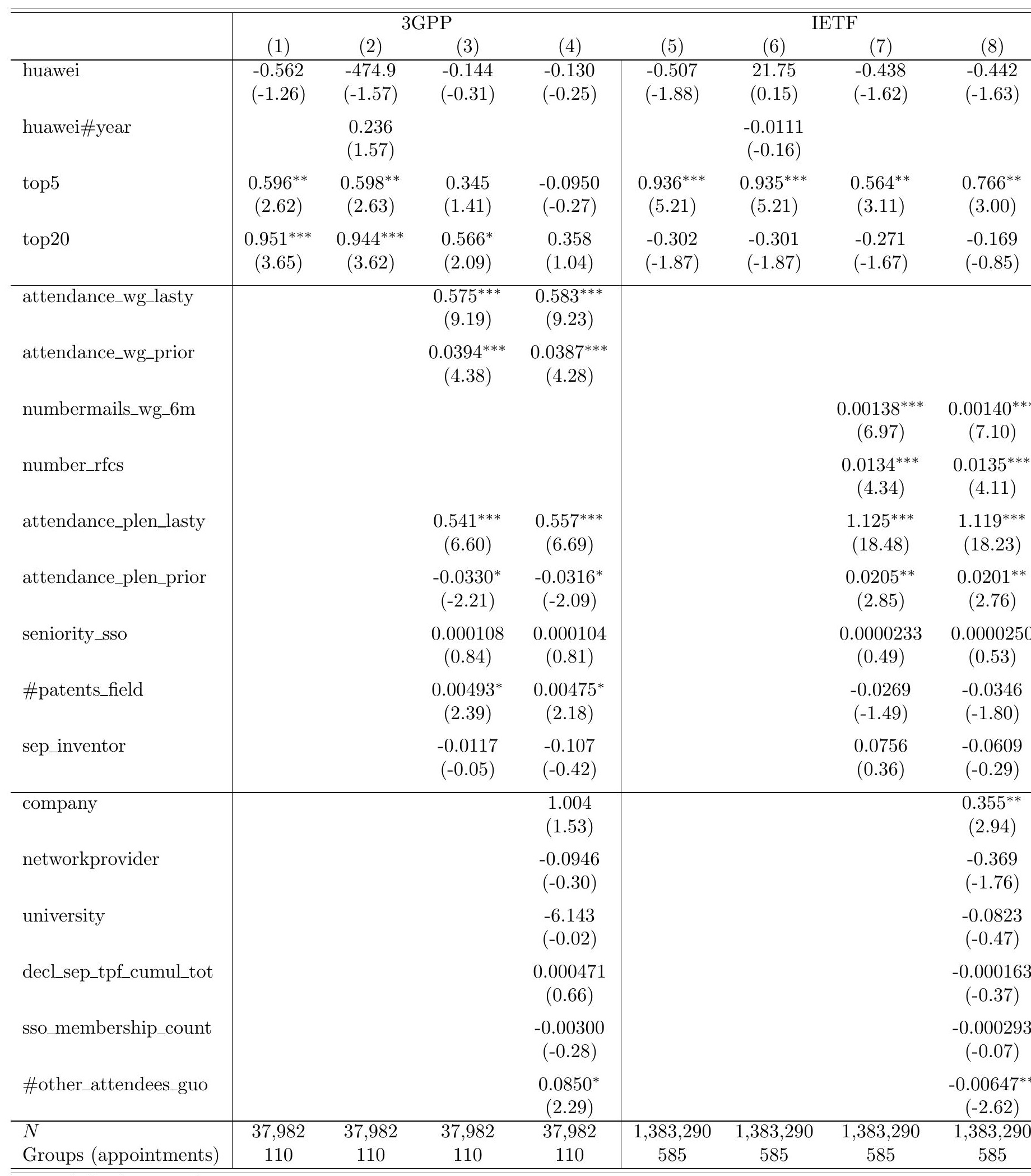

$t$ statistics in parentheses

${ }^{*} p<0.05,{ }^{* *} p<0.01,{ }^{* * *} p<0.001$

Table 3: Conditional logit regression analysis: who is appointed to become working group chair - affiliates of Huawei, other top competitors for SDO leadership, and other attendees 
by individual characteristics. In particular, experience (both within the working group, and the SDO more generally) is a relevant predictor of appointment to chair positions. Patent inventorship is a significant and relevant predictor of chair appointments at 3GPP, but not at IETF. Chair appointments at IETF are, however, significantly predicted by past contributions to IETF, such as RFC authorship and, most importantly, participation in the working group-specific mailing lists. ${ }^{43}$

\subsection{Labor market mobility of individual attendees}

The conditional logit analyses described in Section 4.4 can identify the role of different observable firm- and individual-level characteristics. They cannot, however, account for unobservable individual characteristics, which may differ between affiliates of different organizations, and correlate with chances of appointment to chair positions. The higher likelihood for individuals affiliated with Top 5 affiliations to be appointed to IETF leadership positions may e.g. reflect affiliation effects (e.g. a greater willingness to make employees available for SDO work) or unobserved individual characteristics (e.g. "ability"). Conversely, individual characteristics (such as SDO experience) may hide affiliation effects, as affiliations more eager to acquire SDO leadership positions are also susceptible of encouraging their employees to attend a larger number of SDO meetings.

To disentangle affiliation- and individual-level effects, we take advantage of individuals' changes of affiliation. To study affiliation changes of individuals over time, we build a somewhat narrower dataset of individuals with multiple SDO attendance records, and without irresolvable data conflicts (e.g. no affiliation information for any meeting; multiple affiliations for the same meeting or for different meetings on the same day; and back-andforth changes between different affiliations). At the time we first observe an individual attending an SDO meeting with a particular affiliation, $16.2 \%$ of these individuals have had prior SDO experience with a different affiliation (Table 10 in Appendix A.2). We will particularly focus on cases of changes between two different affiliations, for which we observe the individual in the attendance data over at least two years both before and after the change of affiliation. There are 5,250 such changes of affiliations in our data - this is the source of variation that we exploit for our empirical analysis.

\subsubsection{Recruitments of experienced SDO attendees}

As a first step, we analyze data on affiliation changes to descriptively study different companies' strategies of building the SDO experience that is required to fill SDO leadership positions (see Section 4.4). Figure 5 (Appendix A.2) displays the composition of different cohorts of attendees affiliated with different affiliations. For every year in which a company participates in an SDO, its population of affiliates consists in repeat attendees (those who have already attended SDO meetings for this affiliation in previous years), novices (have never attended an SDO meeting in our sample), new hires (have previously attended SDO

\footnotetext{
${ }^{43}$ We are concerned about a potential reverse causality for this variable, as individuals who have already learned that they will be the group's next chair begin sending larger numbers of messages to the group's mailling list (partly adminstrative in nature). To attenuate this concern, we generally exlude e-mails from the six months preceding the meeting at which we observe the new chair from the count.
} 


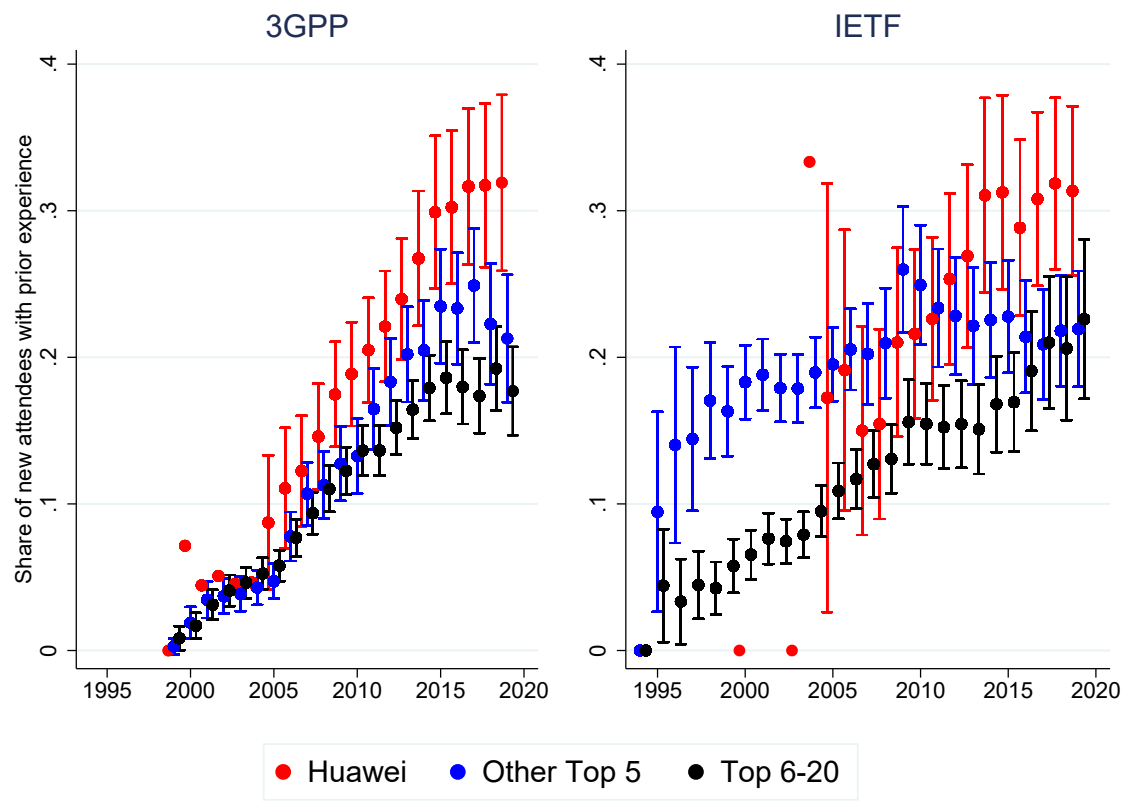

Figure 3: Percentage of an affiliation's new attendees with previous SDO experience, 5 year moving averages

meetings, but with a different affiliation), and those that entered the company's workforce through mergers or acquisition. Having entered later than its leading competitors, in any given year, Huawei's workforce comprises a higher share of novices and recent hires. Novices constitute a smaller share of the workforce of Top 5 than of other Top 20 companies.

Table 10 (Appendix A.2) compares the previous SDO experience of individuals at the time when they begin attending SDO meetings with a certain affiliation. 365 Huawei affiliates $(24.3 \%)$ already had prior SDO experience when they first attended an SDO meeting with their Huawei affiliation. This is a significantly larger share than the one observed for other leading companies, and within the general population of attendees. Unlike for other large companies, mergers and acquisitions played no significant role in building Huawei's workforce of SDO attendees (Table 11, Appendix A.2). ${ }^{44}$

The difference between Huawei and other companies is partly due to timing - as Huawei entered later, more individuals began their work for Huawei when there already existed a large pool of experienced SDO attendees. As visible from Figure 3, the share of new employees with prior SDO experience has grown generally over time for all large companies. Nevertheless, timing alone does not explain the difference between Huawei and other firms. Furthermore, the difference between Huawei and other firms has grown over time, at both $3 \mathrm{GPP}$ and IETF. In particular in more recent years, when Huawei already had a significant presence in SDOs, it recruited significant numbers of experienced SDO attendees from other affiliations.

\footnotetext{
${ }^{44}$ The acquisition of Neul Limited is the only acquisition by Huawei that resulted in transfers of affiliation in our dataset. This contrasts with more significant numbers of affiliation transfers in the context of acquistions by Ericsson (e.g. Telcordia, Marconi, Torrent Networking), Qualcomm (CSR, Flarion, Digital Fountain), and particularly by Nokia ( 80 affiliation transfers from Alcatel-Lucent alone, which itself drew 70 and 63 affiliates from Alcatel and Lucent, respectively). Nokia is also the origin of 34 transfers related to the spinoff of Renesas, one of the largest spinoffs in terms of number of SDO attendees.
} 


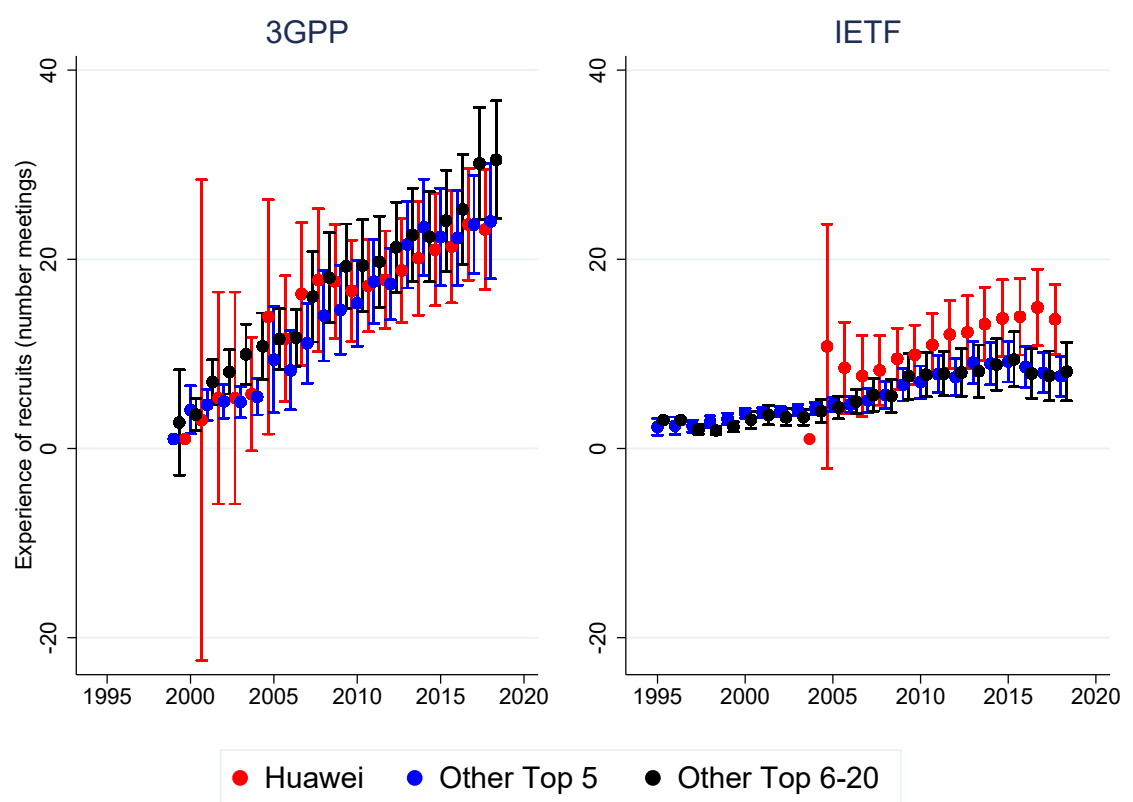

Figure 4: Average experience of new attendees with previous SDO experience, 5 year moving averages

Huawei not only stands out in terms of the number of people with SDO experience that it recruits. At IETF (but not at 3GPP), it also recruits individuals that have significantly more experience on average than the individuals recruited by other affiliations (Figure 4). Given that there are only three IETF meetings per year to attend, the difference in meeting attendance experience between Huawei recruits and the recuits of other top companies is not only statistically significant, it is also impressive in magnitude, and also has widened over recent years. Targeted recruitments of significant numbers of seasoned IETF veterans are perhaps the most salient indication of Huawei's SDO leadership aspirations. While unique to Huawei in recent years, this pattern of building a leadership position through targeted recruiments is not entirely unprecedented. In the late 1990s, Juniper Networks grew in few years to become the principal challenger of Cisco's then-dominant lead over IETF leadership - in large parts through large numbers of recruitments of experienced IETF attendees, both from Cisco itself and from other (mostly large) affiliations.

\subsubsection{Effects of holding a chair position on labor market mobility}

While the descriptive evidence suggests that recruiting experienced SDO participants plays a significant role in the strategy of Huawei and other entrants with SDO leadership aspirations, it does not prove that individuals are recruited because they have significant SDO experience, and that employers value this experience becaus it makes these individuals competitive in selections of SDO leadership. Employers may value SDO experience for other reasons, and SDO experience may simply correlate with characteristics particularly valued by certain employers.

In order to go one step further, we analyze the effect of being appointed to a SDO working group chair position on future affiliation changes, in particular changes to one of the affiliations competing for SDO leadership. We address this question using duration analysis - any individual attending SDO meetings with a particular affiliation is "at risk" 
of changing affiliation at any future meeting (observations of individuals ceasing to attend SDO meetings are censored, i.e. we don't know whether they remain with their employer or change affiliation), and we can assess the factors influencing the hasard of such affiliation changes (as compared with the baseline hasard of affiliation change, which decreases in the time that an individual has held a particular affiliation). Affiliation changes can only be observed at meetings; but duration analysis allows us to account for the different lapses of time between different meetings (we use regular time, i.e. dates, as the time variable in our analysis).

We can first analyze the general effect of appointments to chair positions on any change of affiliation. We are however most interested in the effect of appointments to chair positions on the specific hasard of transitions to specific types of affiliations - those most intensely competing for SDO leadership. We thus face a situation with competing risks: attendees may continue attending with the same affiliation (survival), change affiliation to one of the leading competitors for SDO leadership (failure event), change affiliation to any other organization (competing risk), or cease attending any of the SDOs in our sample (censoring). To account for these multiple possible outcomes, we use competing risk regression analysis for most of the analysis in this section.

We present the results of the pooled analysis for all SDOs (i.e., effect of appointment to any chair position on the likelihood of affiliation changes for attendees of any of the SDOs in our sample) in the following Table 4, and SDO-specific results for 3GPP and IETF in Tables Y and Z in Appendix A.X.

Overall, our empirical results offer support for Hypotheses 3a and 3b: Huawei and other leading competitors for SDO leadership disproportionately recruit experienced SDO participants. At IETF (and not at 3GPP), participants recruited by Huawei are also significantly more experienced, on average, than participants recruited by other top affiliations. We find similar differences, consistent with Hypothesis 3b, regarding the effect of appointments to chair positions on affiliation changes: while appointment to an SDO chair position is generally associated with an increased hazard of affiliation change, appointment to an IETF chair position has a disproportionately large effect on the specific hazard of changing to a top affiliation, including Huawei. The specific hazard of changing to a top affiliation does not differ significantly from the general hazard of affiliation change in the case of an appointment to a $3 \mathrm{GPP}$ chair position, and the effect on the even more specific hazard of changing affiliation to Huawei is statistically indistiguishable from zero (this may, however, be simply due to the lower number of observed "failures" - i.e. transfers to Huawei). The results do not change significantly when excluding Chinese nationals from the analysis.

Importantly, the effect of appointments to chair position on the hazard of affiliation change does not appear to be driven by companies' willingness to recruit active chairs. Distinguishing between active chair positions and any past chair experience, we don't find that active chair positions have a more significant effect on the hazard of affiliation change (or the specific hazard of affiliation change to a particular type of affiliation) than past, concluded chair positions. Past chair experience however is also a highly significant predictor of appointment to new chair positions - it is a significant component of individuals' standing within SDOs, which generally predicts that individuals are attractive to affiliations with significant stakes in standardization. 


\begin{tabular}{|c|c|c|c|c|c|c|c|c|}
\hline \multirow[b]{2}{*}{ chairedgroups } & $(\mathrm{Cox})$ & (2) & $(\mathrm{CR}$, Top 5$)$ & Top 5) & (CR, Huawei) & $\begin{array}{c}(6) \\
\text { dawei) }\end{array}$ & \multicolumn{2}{|c|}{ (CR, Huawei,ex. China) } \\
\hline & $\begin{array}{c}0.0424^{* * *} \\
(4.54)\end{array}$ & $\begin{array}{c}0.0399^{* * *} \\
(3.52)\end{array}$ & $\begin{array}{c}0.0623^{* *} \\
(2.86)\end{array}$ & $\begin{array}{c}0.0518^{*} \\
(2.03)\end{array}$ & $\begin{array}{c}0.0549 \\
(1.30)\end{array}$ & $\begin{array}{c}0.0515 \\
(1.11)\end{array}$ & $\begin{array}{c}0.0695 \\
(1.69)\end{array}$ & $\begin{array}{c}0.0628 \\
(1.37)\end{array}$ \\
\hline active_chair_positions & & $\begin{array}{c}0.00968 \\
(0.40)\end{array}$ & & $\begin{array}{c}0.0432 \\
(0.98)\end{array}$ & & $\begin{array}{c}0.0148 \\
(0.23)\end{array}$ & & $\begin{array}{c}0.0291 \\
(0.48)\end{array}$ \\
\hline attendance_cumul & $\begin{array}{c}0.00291^{* * *} \\
(4.44)\end{array}$ & $\begin{array}{c}0.00291^{* * *} \\
(4.44)\end{array}$ & $\begin{array}{c}0.00576^{* * *} \\
(5.24)\end{array}$ & $\begin{array}{c}0.00578^{* * *} \\
(5.26)\end{array}$ & $\begin{array}{c}0.00553^{* * *} \\
(3.81)\end{array}$ & $\begin{array}{c}0.00554^{* * *} \\
(3.81)\end{array}$ & $\begin{array}{c}0.00545^{* * *} \\
(3.76)\end{array}$ & $\begin{array}{c}0.00549^{* * *} \\
(3.78)\end{array}$ \\
\hline seniority & $\begin{array}{c}0.0000561^{* * *} \\
(3.98)\end{array}$ & $\begin{array}{c}0.0000561^{* * *} \\
(3.99)\end{array}$ & $\begin{array}{c}0.0000482 \\
\quad(1.40)\end{array}$ & $\begin{array}{c}0.0000479 \\
\quad(1.38)\end{array}$ & $\begin{array}{c}0.0000612 \\
\quad(1.11)\end{array}$ & $\begin{array}{c}0.0000611 \\
\quad(1.11)\end{array}$ & $\begin{array}{c}-0.00000103 \\
(-0.02)\end{array}$ & $\begin{array}{c}-0.00000132 \\
(-0.02)\end{array}$ \\
\hline patent_count & $\begin{array}{c}0.0000324 \\
(0.01)\end{array}$ & $\begin{array}{c}0.0000378 \\
(0.02)\end{array}$ & $\begin{array}{c}0.00615 \\
(1.92)\end{array}$ & $\begin{array}{c}0.00614 \\
(1.92)\end{array}$ & $\begin{array}{c}0.00726 \\
(1.86)\end{array}$ & $\begin{array}{c}0.00725 \\
(1.86)\end{array}$ & $\begin{array}{c}0.00437 \\
(0.95)\end{array}$ & $\begin{array}{c}0.00435 \\
(0.95)\end{array}$ \\
\hline sep_count & $\begin{array}{c}-0.0148^{*} \\
(-2.38)\end{array}$ & $\begin{array}{c}-0.0148^{*} \\
(-2.38)\end{array}$ & $\begin{array}{c}-0.0119 \\
(-0.99)\end{array}$ & $\begin{array}{c}-0.0118 \\
(-0.98)\end{array}$ & $\begin{array}{c}-0.00911 \\
(-0.56)\end{array}$ & $\begin{array}{c}-0.00909 \\
(-0.56)\end{array}$ & $\begin{array}{c}-0.00376 \\
(-0.21)\end{array}$ & $\begin{array}{c}-0.00371 \\
(-0.21)\end{array}$ \\
\hline China & $\begin{array}{c}0.0164 \\
(0.17)\end{array}$ & $\begin{array}{c}0.0166 \\
(0.17)\end{array}$ & $\begin{array}{c}1.023^{* * *} \\
(3.64)\end{array}$ & $\begin{array}{c}1.024^{* * *} \\
(3.64)\end{array}$ & $\begin{array}{c}2.131^{* * *} \\
(4.58)\end{array}$ & $\begin{array}{c}2.131^{* * *} \\
(4.58)\end{array}$ & $\begin{array}{l}0 \\
(.)\end{array}$ & $\begin{array}{c}0 \\
(.)\end{array}$ \\
\hline Europe & $\begin{array}{c}-0.311^{* * *} \\
(-3.65)\end{array}$ & $\begin{array}{c}-0.311^{* * *} \\
(-3.65)\end{array}$ & $\begin{array}{l}0.331 \\
(1.23)\end{array}$ & $\begin{array}{l}0.330 \\
(1.23)\end{array}$ & $\begin{array}{l}0.603 \\
(1.29)\end{array}$ & $\begin{array}{l}0.602 \\
(1.29)\end{array}$ & $\begin{array}{l}0.709 \\
(1.52)\end{array}$ & $\begin{array}{l}0.708 \\
(1.51)\end{array}$ \\
\hline Japan & $\begin{array}{c}-0.589^{* * *} \\
(-5.50)\end{array}$ & $\begin{array}{c}-0.588^{* * *} \\
(-5.50)\end{array}$ & $\begin{array}{c}-0.980^{*} \\
(-2.46)\end{array}$ & $\begin{array}{c}-0.979^{*} \\
(-2.46)\end{array}$ & $\begin{array}{l}-1.055 \\
(-1.43)\end{array}$ & $\begin{array}{l}-1.055 \\
(-1.43)\end{array}$ & $\begin{array}{l}-0.934 \\
(-1.27)\end{array}$ & $\begin{array}{l}-0.934 \\
(-1.26)\end{array}$ \\
\hline Korea & $\begin{array}{c}-0.479^{* * *} \\
(-3.84)\end{array}$ & $\begin{array}{c}-0.478^{* * *} \\
(-3.84)\end{array}$ & $\begin{array}{c}-1.323^{*} \\
(-2.35)\end{array}$ & $\begin{array}{c}-1.322^{*} \\
(-2.35)\end{array}$ & $\begin{array}{c}-14.30^{* * *} \\
(-31.82)\end{array}$ & $\begin{array}{c}-14.30^{* * *} \\
(-31.82)\end{array}$ & $\begin{array}{c}-14.91^{* * *} \\
(-33.13)\end{array}$ & $\begin{array}{c}-14.92^{* * *} \\
(-33.14)\end{array}$ \\
\hline North America & $\begin{array}{l}0.140 \\
(1.67)\end{array}$ & $\begin{array}{l}0.139 \\
(1.66)\end{array}$ & $\begin{array}{c}0.551^{*} \\
(2.07)\end{array}$ & $\begin{array}{c}0.549^{*} \\
(2.06)\end{array}$ & $\begin{array}{l}0.539 \\
(1.14)\end{array}$ & $\begin{array}{l}0.538 \\
(1.14)\end{array}$ & $\begin{array}{l}0.670 \\
(1.43)\end{array}$ & $\begin{array}{l}0.668 \\
(1.42)\end{array}$ \\
\hline year & $\begin{array}{c}-0.0472^{* * *} \\
(-13.16)\end{array}$ & $\begin{array}{c}-0.0472^{* * *} \\
(-13.16)\end{array}$ & $\begin{array}{c}-0.0246^{* *} \\
(-2.75) \\
\end{array}$ & $\begin{array}{c}-0.0245^{* *} \\
(-2.74) \\
\end{array}$ & $\begin{array}{c}0.0366^{*} \\
(2.54) \\
\end{array}$ & $\begin{array}{c}0.0366^{*} \\
(2.54) \\
\end{array}$ & $\begin{array}{c}0.0736^{* * *} \\
(5.18) \\
\end{array}$ & $\begin{array}{c}0.0737^{* * *} \\
(5.19) \\
\end{array}$ \\
\hline $\mathrm{N}$ & 178,157 & 178,157 & 178,157 & 178,157 & 167,972 & 167,972 & 156,606 & 156,606 \\
\hline Subjects & 12,918 & 12,918 & 12,918 & 12,918 & 12,321 & 12,321 & 11,371 & 11,371 \\
\hline Failure & 3,459 & 3,459 & 502 & 502 & 194 & 194 & 136 & 136 \\
\hline Competing & & & 2,957 & 2,957 & 3,172 & 3,172 & 2,983 & 2,983 \\
\hline
\end{tabular}

$t$ statistics in parentheses

${ }^{*} p<0.05,{ }^{* *} p<0.01,{ }^{* * *} p<0.001$

Table 4: Effect of appointment to chair positions on affiliation changes any SDO 


\subsubsection{Effects of affiliation on chair appointments}

Next, we will use labor market mobility of SDO attendees to control for unobserved heterogeneity in individual characteristics, and separately identify the role of affiliation characteristics for apponitments to SDO chair positions. Many unobserved individual-level characteristics are largely constant over time (such as intrinsic ability), or pre-determined with respect to the period of the individual's participation in SDOs (e.g. education). As we observe individuals' careers accross different affiliations, we can test whether any given individual is more likely to be appointed to a chair position while being affiliated with an organization of certain characteristis (controlling for seniority).

Specifically, we explain the likelihood of individuals' appointments to leadership positions as a function of the characteristics of their current affiliation, controlling for time-invariant heterogeneity in individual characteristics by including individuum fixed effects. To attenuate reverse causation concerns (as we have shown SDO experience to have an effect on labor market mobility), we generally focus on new appointments as explained variable, as explained by the characteristics of the affiliation held by individuals in the previous semester. One potential concern with this approach is that several important individual characteristics do change over time in ways that differ from one individual to the other. Especially for individuals observed over long stretches of time, individuum fixed effects may not fully control for unobserved heterogeneity in individual characteristics.

As an alternative approach, we thus focus on individual affiliation changes, and compare the likelihood of chair appointment in the three years before and after the change. Focusing on single changes between two different affiliations, as opposed to tracing entire careers across multiple affiliations, we compare individuals' likelihood of being appointed to chair positions at less distant points in time. We corroborate the robustness of our results to concerns about reverse causation, using affiliation changes resulting from changes in corporate structure (mergers, acquistions, spinoffs, and transfers of firms from one parent to the other). Causation of these changes in corporate structure is established at a significantly higher level of aggregation, ruling out that affiliation changes are immediately caused by an individual's impending appointment to an SDO leadership position.

While more robust to time-variant, but slow-moving unobserved individual characteristics and to potential reverse causation, these analyses are susceptible to other concerns, such as measurement error (both the timing of affiliation change and appointment to chair position are inferred from the attendance data, and subject to error), and anticipation (individuals may anticipate a change of affiliation or an appointment to an SDO leadership position, which may affect their labor market mobility or SDO participation decisions). The longer time span of observation in the fixed effect analysis in turn attenuates concerns about measurement error and anticipation. As the two sets of analyses are subject to orthogonal concerns, consistency between the results of the different analyses thus would give us some confidence in our preferred (causal) interpretation of observable correlations between affiliation characteristics and appointments to chair positions.

We present the results our preferred specification (changes in the likelihood of chair appointments before and after changes to the corporate structure) in the following Tables 5 and 6. The remainder of the results are presented in Appendix A.4: The resuts of the fixed effect logit analysis of new chair appointments are presented in Tables 14 and 15 . 


\begin{tabular}{|c|c|c|c|c|c|c|}
\hline & (1) & (2) & (3) & (4) & $\begin{array}{c}(5) \\
(M \& A)\end{array}$ & $\begin{array}{c}(6) \\
\text { (Spinoffs) }\end{array}$ \\
\hline top5 & $\begin{array}{c}-0.00748 \\
(-1.21)\end{array}$ & & & & & \\
\hline top20 & & $\begin{array}{c}0.0203 \\
(1.06)\end{array}$ & & & & \\
\hline network op & & & $\begin{array}{c}-0.0144 \\
(-0.93)\end{array}$ & & & \\
\hline \#decl_SEP & & & & $\begin{array}{c}-0.0000202^{*} \\
(-2.01)\end{array}$ & & \\
\hline after & $\begin{array}{l}0.0351 \\
(1.11)\end{array}$ & $\begin{array}{c}0.0330 \\
(1.10)\end{array}$ & $\begin{array}{l}0.0349 \\
(1.10)\end{array}$ & $\begin{array}{l}0.0387 \\
(1.15)\end{array}$ & $\begin{array}{c}0.0422 \\
(0.91)\end{array}$ & $\begin{array}{c}0.00689 \\
(0.93)\end{array}$ \\
\hline seniority & $\begin{array}{c}-0.0000254 \\
(-1.23)\end{array}$ & $\begin{array}{c}-0.0000248 \\
(-1.23)\end{array}$ & $\begin{array}{c}-0.0000254 \\
(-1.23)\end{array}$ & $\begin{array}{c}-0.0000252 \\
(-1.18)\end{array}$ & $\begin{array}{c}-0.0000281 \\
(-0.94)\end{array}$ & $\begin{array}{c}-0.00000555 \\
(-1.25)\end{array}$ \\
\hline _cons & $\begin{array}{c}0.0542 \\
(1.64)\end{array}$ & $\begin{array}{c}0.0448 \\
(1.73)\end{array}$ & $\begin{array}{c}0.0543 \\
(1.60)\end{array}$ & $\begin{array}{c}0.0536 \\
(1.61)\end{array}$ & $\begin{array}{c}0.0549 \\
(1.30)\end{array}$ & $\begin{array}{c}0.0176^{*} \\
(2.03)\end{array}$ \\
\hline$N$ & 2,567 & 2,567 & 2,567 & 2,460 & 1,711 & 1,546 \\
\hline Groups & 254 & 254 & 254 & 254 & 173 & 87 \\
\hline
\end{tabular}

Table 5: New chair appointments, 3 years before and after change of affiliation - mergers, acquistions, and spinoffs - 3GPP

The results of the analysis of individual affiliation changes (not restricted to changes in corporate structure) are presented in Tabled 16 and 17.

The results are largely consistent between the different specifications, but differ between SDOs. Being affiliated with a leading (Top 5) competitor for SDO leadership increases an individual's chances of appointment to a working group chair position at IETF (significant at $10 \%$ for both affiliation changes resulting from corporate structure events, and in the fixed effect estimation, highly significant at $1 \%$ in the broader analysis of individual affiliation changes). This is consistent with significant positive effects associated with changes to a company affiliation (e.g. from a university or public administration; significant at $5 \%$ in both the fixed effect analysis and the broader analysis of individual affiliation changes, not applicable in the corporate structure changes analysis). Changes to affiliations with larger numbers of declared SEPs ${ }^{45}$ are also (albeit less consistently) associated with significant increases in the likelihood of appointments to chair positions (significant at $10 \%$ in the corporate structure event analysis, at $1 \%$ and $5 \%$ in the fixed effect analysis; not significant in the broader affiliation change analysis). Overall, these results present a fairly consistent picture - affiliation with an entity that has significant stakes in ICT standardization increases the likelihood of appointment to IETF chair positions.

\footnotetext{
${ }^{45}$ Counts of declared SEP are measured at the beginning of the individual's SDO career in the fixed effect analysis, and in the year of affiliation change for the broader affiliation change analysis. For the narrower analysis of affiliation changes resulting from corporate structure events; the declared SEPs of the acquired firm are added to the stock of the acquiring parent company.
} 


\begin{tabular}{|c|c|c|c|c|c|c|}
\hline & (1) & (2) & (3) & (4) & $\begin{array}{c}(5) \\
(\mathrm{M} \& \mathrm{~A})\end{array}$ & $\begin{array}{c}(6) \\
\text { Spinoffs }\end{array}$ \\
\hline top5 & $\begin{array}{c}0.0162 \\
(1.95)\end{array}$ & & & & & \\
\hline top20 & & $\begin{array}{c}0.00320 \\
(0.37)\end{array}$ & & & & \\
\hline network_op & & & $\begin{array}{c}0.00461 \\
(0.73)\end{array}$ & & & \\
\hline \#decl_SEP & & & & $\begin{array}{c}0.00117 \\
(1.60)\end{array}$ & & \\
\hline after & $\begin{array}{c}-0.0110 \\
(-1.06)\end{array}$ & $\begin{array}{c}-0.00861 \\
(-0.81)\end{array}$ & $\begin{array}{c}-0.00797 \\
(-0.83)\end{array}$ & $\begin{array}{c}-0.00878 \\
(-0.95)\end{array}$ & $\begin{array}{c}-0.00849 \\
(-0.85)\end{array}$ & $\begin{array}{c}-0.0203 \\
(-1.50)\end{array}$ \\
\hline seniority & $\begin{array}{c}0.00000290 \\
(0.39)\end{array}$ & $\begin{array}{c}0.00000320 \\
(0.43)\end{array}$ & $\begin{array}{c}0.00000325 \\
\quad(0.43)\end{array}$ & $\begin{array}{c}0.00000320 \\
\quad(0.39)\end{array}$ & $\begin{array}{c}0.00000601 \\
\quad(0.79)\end{array}$ & $\begin{array}{c}0.00000878 \\
(1.16)\end{array}$ \\
\hline _cons & $\begin{array}{c}0.0139 \\
(1.02)\end{array}$ & $\begin{array}{c}0.0130 \\
(0.94)\end{array}$ & $\begin{array}{c}0.0133 \\
(0.98)\end{array}$ & $\begin{array}{c}0.00920 \\
(0.57)\end{array}$ & $\begin{array}{c}0.00732 \\
(0.56)\end{array}$ & $\begin{array}{c}-0.00256 \\
(-0.22)\end{array}$ \\
\hline$N$ & 2,953 & 2,953 & 2,953 & 2,441 & 2,763 & 1,463 \\
\hline Groups & 289 & 289 & 289 & 289 & 270 & 80 \\
\hline
\end{tabular}

$t$ statistics in parentheses

${ }^{*} p<0.05,{ }^{* *} p<0.01,{ }^{* * *} p<0.001$

Table 6: New chair appointments, 3 years before and after change of affiliation - mergers, acquistions, and spinoffs - IETF

No such consistent positive effect is observable at 3GPP. Affiliation with one of the Top 5 or Top 20 leading affiliations has no significant effect in any of the specifications. If anything, other measures of an affiliation's stakes in standardization point to a negative effect of being affiliated with a more influential stakeholder. Affiliation changes to or from companies are associated with highly significant negative effects in the broader affiliation change analysis (but not in the fixed effect specification). ${ }^{46}$ Being affiliated with a company owning larger numbers of declared SEPs is associated with a negative effect on the likelihood of being appointed to a 3GPP chair position in the corporate structure event analysis and the fixed effect regression, but not in the broader affiliation change analysis.

The evidence thus is broadly consistent with Hypotheses 4a and 4c: affiliation with a leading competitor for SDO leadership is associated with a higher likelihood of being appointed to chair positions (Hypothesis 4a); but this effect is limited to IETF, an SDO where these companies' greater incentives and ability to support their employees' leadership aspirations are not counteracted by SDO attempts to balance the representation of different interests (Hypothesis 4a). Analyses of the specific effect of being affiliated with Huawei (Hypothesis 4b), however, are inconclusive. There is a signficant positive effect of being affiliated with Huawei in the broader affiliation change analysis at $3 \mathrm{GPP}$, which is not

\footnotetext{
${ }^{46}$ Affilation with entities other than companies is rare at 3GPP, however, and mostly concerns Public Research Institutes, many of which in Asia, which are heavily invested in standards-related research. This differs from IETF, where there are many academics whose affiliation is unlikely to have significant stakes in IETF standardization outcomes, and where being affiliated with a company as opposed to a university is a proxy for the presence of commercial interests in standardization (Simcoe, 2012).
} 
corroborated by the fixed effect analysis. There is no significant effect in either specification for the case of IETF. Because of the very low number of transfers to Huawei that can be attributed to changes in corporate structure, our preferred estimation does not produce Huawei-specific results.

\section{Discussion: Institutional and legal implications}

\subsection{Effect on chairs' affiliation on the likelihood of leadership appoint- ment}

The empirical results reveal the importance of both individual- and affiliation-level determinants for being selected to the SDO leadership. There are commonly three factors determining whether a particular inidivdual may be appointed to a chair's position. First, individual motivation: individuals may have incentives to acquire leadership positions as a personal career strategy or to increase their influence in a particular domain of expertise. Second, support by the individual's employer: while appointment to SDO leadership roles may constitute a conflict of commitment with respect to the individual's regular work duties, companies may encourage their employees to acquire leadership positions as a form of an investment in standardization activities, since leadership positions entail certain powers to the incumbents and thus also to their affiliation, allowing them to influence standardization processes and align standards with their views. Third, selection: individuals may be selected as chairs for their individual characteristics, such as their experience and social capital that they have acquired due to their extensive experience in the SDO; but also for reasons that depend on their affiliation, such as the abiity and motivation to commit work time to perform the chair's duties, as well as their willingness to prioritize SDO interests over the potentially competing interests of their affiliation. These three factors act simultaneously, but are often difficult if not impossible to separately identify.

Our empirical observations suggest that individual characteristics, such as an individual track record of SDO participation and technical expertise, are critical factors in the chair apppointment. Individuals holding chair positions are not replaceable at will by their affiliation which, at least in theory, should give them some leverage to oppose a company's agenda that conflicts with the SDO's interests. In fact, executing the agenda of their affiliation may depreciate individuals' social capital by affecting their reputation, which is one of the crucial components for being selected as a chair. This allows us to assume that individual participation provides at least some safeguards against undue influence from the different companies competing for SDO leadership.

However, individuals are unlikely to be motivated to volunteer for chair positions without support from their affiliation, including remuneration for their time and work as an SDO chair, possibly as a part of their employment duties. This support is more likely to be encountered from entities with leadership aspirations, as indicated by the fact that companies competing for SDO leadership are more likely to recruit individuals with SDO-specific social and human capitals. Even though appointments to chair positions are strongly predicted by individual characteristics, chiefly individual experience, leadership positions are thus relatively concentrated in the hands of companies with high levels of participation. Emphasizing individual participation alone is thus not sufficient to insulate 
individuals in SDO leadership positions from their employers' strategic incentives; effective competition in a diverse set of affiliations competing for leadership is needed to support individual ambitions to volunteer for the chair positions, while preserving the independence of individuals holding chair positions from their employers' agenda.

Huawei's strategy to invest in its employees' leadership appointments contributes to mobility to Huawei of those individuals with leadership experience and ambitions. By recruiting large numbers of experienced SDO participants, Huawei is rapidly catching up with its Western competitors, and increases its chances of holding key SDO leadership positions. Nevertheless, individuals are appointed to leadership positions because of their experience and individual qualifications, not because of their affiliation. As evidenced by the data, SDO working group chairs affiliated with Huawei are generally seasoned members of an SDO's community. Furthermore, Huawei's chair positions are disproportionately often held by Western nationals, whereas the overwhelming majority of SDO attendees affiliated with Huawei are Chinese.

For an individual with a given level of experience and expertise, firm-level variables associated with an entity's interest in influencing standardization outcomes nevertheless increase the likelihood of being appointed as chair (i.e. the same individual is more likely to be appointed as a chair if working for a large company; holding all individual characteristics constant). Nevertheless, controlling for firm- and individual-level characteristics, there is nothing peculiar about Huawei, since being affiliated with Huawei neither increases nor decreases the likelihood of being appointed to chair positions.

\subsection{Diversity and balance in SDOs}

Our findings carry important implications for the global standardization ecosystem, its resilience and legitimacy. The apparent over-representation of the West in leadership positions at some of the most important SDOs in the ICT sector, as well as the fact that this over-representation has not fully eroded over time despite the increasing share of Chinese individuals amogn attendees at these SDOs, indicates a serious lack of diversity in these SDOs.

The existing extent of under-representation of Chinese nationals in SDO leadership can in part be explained by mechanical latency, which can be expected to erode over time as new leadership positions will be filled. Indeed, for new chair appointments, Chinese nationals appear competitive. Nevertheless, it appears that even new appointments exhibit a bias towards Western nationals. The continued overselection of Western nationals in the four SDOs cannot be explained by observable SDO experience alone. While Europeans and North Americans tend to have more experience in these SDOs than other individuals, for a given vacancy, individuals from Europe or North America are more likely to be appointed than individuals from other countries with similar levels of SDO experience and a similar technological track record in the field.

The current tendency for leadership appointments to exhibit a bias towards Western individuals is displayed beyond Chinese nationals: considering their experience level and the current share of participation, individuals from highly developed Asian countries, such as Japan and South Korea, are similarly or even more under-represented in recent chair appointments than inidivuals from China. Similarly to Japan, countries in these 
regions are overwhelmingly free-market economies and democratically governed. From this perspective, then, it can be suggested that over-representation of certain Wolrd regions in SDOs' leadership does not appear to be driven by the fundamental economic or political system of attendees' countries of residence.

As we do not observe unsuccessful candidates for chair positions, we cannot distinguish whether Asian individuals are less likely to volunteer to serve as chair or less likely to be selected as chairs when there are competing volunteers from the West, also given that these two factors are likely to be inter-related. Both these potential causal mechanisms are consistent with explanations pointing to cultural differences, as well as language barriers. At least three SDOs in our sample largely originated in a specific region of the world (IEEE-SA and IETF in the U.S., and 3GPP in Europe) as reflected in historical attendance records, and have their roots either in the European governance traditions 47 or in the culture of open and decentralized Internet governance that was developed in North America (Weiser, 2001). Leadership appointments at these SDOs indicate strong regional preferences: at IETF, there is a strark contrast between "Western" and "Asian" representation in the leadership, while at 3GPP, Europeans apointees prevail over significantly unde-represented North Americans, along with the rest of world (apart from China), which allows us to assume that there is a certain "home bias" at 3GPP. We thus suspect that these organizations retain instititutional features, both explicit procedures and implicit norms, that are aligned with the work culture, national institutional regimes and familiarity with participation in standard-setting of their region (Jorissen et al., 2013). An important part of that work culture are expectations with regard to their officials' behaviour in the cultural and organizational context on a particular SDO, as evident from the rules on chairs' conduct in Section 3.1, as well as broader differences in organizational cultures. This allows us to assume that broader differences in organizational cultures may both inhibit non-Western individuals' motivation to volunteer, and the willingness of other SDO participants to select non-Western volunteers. ${ }^{48}$

Our analysis thus shows that so far, SDOs have been unsuccesful to reach a balanced representation of different geographical regions in their leadership, which may have potentially significant adverse consequences for the global difusion of their standards. In particular, continued under-representation of non-Western nationals in leadership positions may demotivate participants from other countries not only to volunteer as chairs, but also to participate in SDOs' processes. Technical contributions by these individuals however play an increasingly important role for standards development, while participation of their affiliations is likely to affect standards' effective influence and uptake in the in high-growth markets, in particular China. Furthermore, next to the extent to which non-Western countries may be willing to implement standars of SDOs whose leadership is tilted towards the West, such geographic leadership imbalances may also weaken these SDOs' interna-

\footnotetext{
$\overline{47}$ The European Telecommunications Standards Institute, one of the European standards bodies, provides 3GPP's secretariat and coordinates its meetings

${ }^{48}$ See for the reference the RFC 7704 which, while noting that "groups with greater diversity make better decisions," also admits that IETF participation culture is rooted in the culture of "well-funded, American, white, male technicians, demonstrating a distinctive and challenging group dynamic, both in management and in personal interactions" https://tools.ietf.org/html/rfc7704. In a similar vein, Baron et al recently observed that the increased diversity of female representation in IETF leadership was induced by changes in the SDOs' informal norms and 1 and societal culture.
} 
tional input legitimacy (Jorissen et al., 2013). Eventually, all these different effects may compound to weaken the SDOs' aspirations to serve a global ICT infrastructure, and exacerbate existing risks of splintering of ICT technology along geographical lines.

Generally, concerns for geographical diversity must be weighed against other important considerations, and in particular stakeholder balance. ${ }^{49}$. Given that affiliations of Asian participants, and in particular China, are less diverse than affiliations of participants from North American and Europe, and that Huawei already holds a significant number of SDO leadership positions despite the under-representation of Chinese nationals, concerns regarding the balance of commercial interests may arise. Furthermore, for some issues, individuals affiliated with Huawei and other Chinese companies, as well as Chinese Public Research Institutes, may pursue similar interests, as there is a larger degree of government coordination of ICT standardization in China than in Western countries (Liu and Cheng, 2014; Pusceddu, 2020).

These considerations could suggest that there is significant potential for tensions between the system of checks and balances between different competing interests, inherent to private standardization, and a more recent concern for geographical balance. Nevertheless, the empirical findings point to a home bias of the different SDOs, historically anchored in Europe and North America, which is largely orthogonal to the politicized distinctions between Global South and Global North or between China and the West. This finding suggests that SDOs have significant room to enhance geographical balance in their leadership without affecting stakeholder balance or risking potential dominance by single entities. At the same time, instances of over-representation of certain stakeholder categories may also emerge from the intrinsic culture and traditions that are still strongly present at the SDOs. As one instance, we observe that network operators continue to be over-represented in chair appointments at $3 \mathrm{GPP}$, and affiliation with a network operator increases the chances of an individual with given characteristics to be appointed to a chair position.

\subsection{Governance traditions in different SDOs}

Our analysis also highlights the relevance of the different governance features and institutional traditions of SDOs. This difference is particularly evident between 3GPP, which exemplifies an entity-based approach and attaches importance to the balance of representation of commercial interests, and IETF, which avoids any formal requirement of balance of interests and empisizes openness of its processes (Baron et al., 2021a). ${ }^{50}$. In this context, IETF's culture of meritocracy and the emphasis on openness and individualbased participation may generate presumption that its leadership exibits more diversity and autonomy fromtheir respective affiliations than the leadership of 3GPP, individuals generally participate as representatives of an organizational member of 3GPP. However, these presumptions are not borne out in the facts: empirically, affiliation characteristics are

\footnotetext{
${ }^{49}$ As exemplified by the issue of improving the representational diversity among IETF leadership and the increasing number of Huawei-affiliated candidates in the recent IETF chair elections https://www.centr.org/news/blog/ietf109-new-chair.html

${ }^{50}$ The exception is the requirement for the composition of IETF's Nominating Committee, where no more than two appointees may hold the same affiliation
} 
more relevant determinants of appointments to leadership positions at IETF than at 3GPP. This suggests that organizations with a governance tradition of explicit and balanced representation of different stakeholders allow individuals to be appointed to leadership positions based on merit, whereas organizations with a "free-for-all" approach are likely to oversample affiliates of dominant entities, since there is no balance requirement that may act as a check on some copanies' superior incentives and ability to invest in their employees' leadership ambitions. An emphasis on individual participation is thus not a sufficient subsitute for balance of stakeholders interests in SDOs.

That said, the perceived relative importance of commercial or geographical balance may differ between SDOs: for instance, some regional and national SDOs require balance of commercial interests for their processes to comply with the applicable administrative or antitrust regulations or for their standars to be transposed into national or regional legislation (Kanevskaia, 2020). Balance of commercial interests is traditionally sought in the entity-based SDOs as 3GPP and OneM2M, where it is also entrenched into their operational frameworks, in contrast with individual-based IETF. At IETF, in contrast, calls for increased diversity and de-Westernization in SDOs become increasingly apparent, including the recent discussions on the use of oppressive and exclusionary language in IETF document ${ }^{51}$ if not taken seriously, this lack of geographical diversity may in the long run entail reputational implications for SDOs, while similarlly, the selective regional preference for SDOs may risk fragmentation of global standardization activities and thus also of global standards.

\section{Conclusion}

This paper contibutes with an empirical analysis of meeting attendance and leadership appointments in the four prominent SDOs, taking into account these SDOs formal rules and informal traditions. This analysis provides insights into the current composition of SDO leadership and offers quantitative evidence of the extent to which concerns of Huawei's capture of ICT standardization, increasingly voiced by the West, are substaniated. It further allows to derive factors that are critical for an individual's appointment to SDO leadership, which in turn allow us to make suggestions regarding the likelihood of certain affiliations to be represented in the leadership of these SDOs.

In both individual and entity-based SDOs, individuals are appointed to the leadership positions for the reason of their human and social capital and individual qualification and experience. This, however, does not take away the fact that affiliation remains important for an individual's chances to volunteer and to be chosen, not least because affiliations competing to lead global standards development are more eager to (financially) support their employees' ambitions to volunteer as SDOs' working group chairs. While Huawei's strategy to increase its influence in SDOs by volunteering its empoyees to SDO leadership may indeed contribute to individuals' mobility to Huawei and thus also increase its chances of acquiring SDO leadership position, the evidence suggests that SDO leadership remains largely dominated by the West. This lack of diversity in the leadership appointments

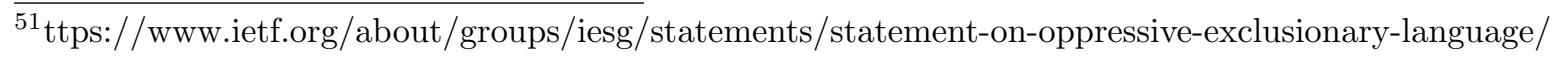


may be explained by mechanical latency that is characteristic for SDOs newcomers, since individual experience is critical for leadership appointments, but arguably also by the cultural and organizational features of Western SDOs and their presumable affect on the leadership ambitions, and chances to be chosen, of non-Western individuals. From the perspective of SDO governance, this lack of diversity in SDO leadership may be considered a defense mechanism against the attempts to capture SDO processes.

Future research that continues examining tendencies in SDOs leadership appointment and linking them with their institutional tenets and formal and informal governance rules may shed more light onto SDOs' mechanism to prevent undue commercial influence on and safeguard the integrity of their processes. In particular, the tension between diversity and balance in SDO governance deserves further attention in academic literature and substantiation with empirical evidence. Likewise, further research is desirable to assess the tendencies in meeting attendance and leadership appointments in SDOs that are not rooted in the tradition of private, decentralized standardization models, and to evaluate the consequences of different patterns and tendencies in leadership appointments for the overal resilience and legitimacy of the current global standardization ecosystem. 


\section{References}

J. Baron and T. Pohlmann. Mapping standards to patents using declarations of standardessential patents. Journal of Economics and Management Strategy, 27(3):504-534, 2018.

J. Baron and D. Spulber. Technology standards and standards organizations: An introduction to the searle center database. Journal of Economics and Management Strategy, 27(3):462-503, 2018.

J. Baron, J. L. Contreras, M. Husovec, P. Larouche, and N. Thumm. Making the rules: The governance of standard development organizations and their policies on intellectual property rights. JRC Science for Policy Report, EUR, 29655, 2019.

J. Baron, J. L. Contreras, and P. Larouche. Balance requirements for standards development organizations: A historical, legal and institutional assessment. Working Paper, 2021a.

J. A. Baron. Participation in the standards organizations developing the internet of things: Recent trends and implications. In Shaping the Future Through Standardization, pages 117-147. IGI Global, 2020.

J. A. Baron, B. Ganglmair, N. Persico, T. Simcoe, and E. Tarantino. Representation is not sufficient for selecting gender diversity. Technical report, National Bureau of Economic Research, 2021b.

K. Blind and A. Mangelsdorf. Motives to standardize: Empirical evidence from germany. Technovation, 48:13-24, 2016.

K. Blind, J. Pohlisch, and A. Zi. Publishing, patenting, and standardization: Motives and barriers of scientists. Research Policy, 47(7):1185-1197, 2018.

K. Blind, A. Lorenz, and J. Rauber. Drivers for companies' entry into standard-setting organizations. IEEE Transactions on Engineering Management, 2020.

A. Bonatti and H. Rantakari. The politics of compromise. American Economic Review, 106(2):229-259, February 2016.

A. Bradford. The Brussels Effect. Oxford University Press, 2020.

J. L. Contreras. Divergent patterns of engagement in internet standardization: Japan, korea and china. Telecommunications Policy, 38(10):914-932, 2014.

P. Delimatsis. Global standard-setting 2.0: How the wto spotlights iso and impacts the transnational standard-setting process. Duke Journal of Comparative and International Law, 28:273, 2018.

H. Dernis and M. Khan. Triadic patent families methodology. 2004.

G. Dokko and L. Rosenkopf. Social capital for hire? mobility of technical professionals and firm influence in wireless standards committees. Organization Science, 21(3):677-695, 2010. 
D. Ernst. Indigenous innovation and globalization: The challenge for china's standardization strategy. D. Ernst, Indigenous Innovation and Globalization: The Challenge for China's Standardization Strategy, 2011.

J. Farrell and G. Saloner. Coordination through committees and markets. RAND Journal of Economics, 19(2):235-252, Summer 1988.

J. Farrell and T. Simcoe. Choosing the rules for consensus standardization. RAND Journal of Economics, 43(2):235-252, Summer 2012.

T. Fischer and J. Henkel. Complements and substitutes in profiting from innovation - a choice experimental approach. Research Policy, 42(2):326-339, 2013.

L. Fleming and D. Waguespack. Scanning the commons? evidence on the benefits to startups participating in open standards development. Management Science, 55(2): 210-223, February 2009.

M. C. Gamito. Europeanization through standardization: Ict and telecommunications. Yearbook of European Law, 37:395-423, December 2018.

M. C. Gamito. From private regulation to power politics: the rise of china in ai private governance through standardisation. ssrn, February 2021.

N. Gandal, N. Gantman, and D. Genesove. Intellectual property and standardization committee participation in the us modem industry. CEPR Discussion Paper No. 4658, Centre for Economic Policy Research, Oct. 2004.

B. Ganglmair, T. Simcoe, E. Tarantino, et al. Learning when to quit: An empirical model of experimentation in standards development. Technical report, University of Bonn and University of Mannheim, Germany, 2018.

C. S. Gibson. Globalization and the technology standards game: Balancing concerns of protectionism and intellectual property in international standards. 2007. Suffolk University Law School Faculty Publications Paper 43.

L. Goerke and M. Holler. Voting on standardisation. Public Choice, 83:337-351, 1995.

H. Halpin. The crisis of standardizing drm: the case of w3c encrypted media extensions. In International Conference on Security, Privacy, and Applied Cryptography Engineering, pages 10-29. Springer, 2017.

A. Harcourt, G. Christou, and S. Simpson. Global Standard Setting in Internet Governance. Oxford University Press, 2020.

S. Hoffman, D. Lazanski, and E. Taylor. Standardising the splinternet: how china's technical standards could fragment the internet. Journal of Cyber Policy, 5(2):239-264, August 2020.

K. Husted and S. Michailova. Dual allegiance and knowledge sharing in inteer-firm r\&d coollaborations. Organizational Dynamics, 39(1):37-47, 2010.

J. Isaak. The role of individuals and social capital in posix standardization. International Journal of IT Standards and Standardization Research (IJITSR), 4(1):1-23, 2006. 
A. Jorissen, N. Lybaert, R. Orens, and L. Van der Tas. A geographic analysis of constituents' formal participation in the process of international accounting standard setting: Do we have a level playing field? Journal of Accounting and Public Policy, 32(4):237-270, 2013.

O. Kanevskaia. Governance of ict standardization: Due process in technocratic decisionmaking. NCJ Int'l L., 45:549, 2020.

B. Kang and K. Motohashi. Essential intellectual property rights and inventors' involvement in standardization. Research Policy, 44(2):483-492, March 2015.

P. Larouche and F. Schuett. Repeated interaction in standard setting. Journal of Economics $\&$ Management Strategy, 28(3):488-509, 2019.

W. Lehr. Compatibility standards and industry competition: Two case studies. Economics of Innovation and New Technology, 4(2):97-112, 1996.

A. Leiponen. Competing through cooperation: Standard-setting in wireless telecommunications. Management Science, 54(11):1904-1919, November 2008.

M. A. Lemley and C. Shapiro. Patent holdup and royalty stacking. Texas Law Review, 85, 2007. Stanford Law and Economics Olin Working Paper No. 324.

J. Lerner and J. Tirole. Standard-essential patents. Journal of Political Economy, 123(3): 547-586, 2015.

X. Liu and P. Cheng. National strategy of indigenous innovation and its implication to china. Asian Journal of Innovation and Policy, 3(1):117-139, 2014.

M. I. Marpet. An ethical issue in voluntary-consensus-standards development: A decisionscience view. Journal of Business Ethics, 17(1):1701-1716, March 1998.

M. Murphree and D. Breznitz. Indigenous digital technology standards for development: the case of china. Journal of International Business Policy, 1:234-252, 2018.

C. N. Murphy and J. Yates. The International Organization for Standardization (ISO): global governance through voluntary consensus. Routledge, 2009.

P. Pusceddu. Hic sunt dracones? mapping the legal framework of china's innovation policy: Standardization and iprs. IIC-International Review of Intellectual Property and Competition Law, 51:559-593, 2020.

A. L. Russell. Open standards and the digital age. Cambridge University Press, 2014.

M. Rysman and T. Simcoe. Patents and the performance of voluntary standard-setting organizations. Management Science, 54(11):1920-1934, November 2008.

M. Shoebridge. Chinese cyber espionage and the national security risks Huawei poses to $5 G$ networks. Macdonald-Laurier Institute for Public Policy, 2018.

T. Simcoe. Standard setting committees: Consensus governance for shared technology platforms. American Economic Review, 102(1):305-336, February 2012.

C. Sternitzke. Defining triadic patent families as a measure of technological strength. Scientometrics, 81(1):91-109, 2009. 
P. J. Weiser. Internet governance, standard setting, and self-regulation. N. Ky. L. Rev., 28:822, 2001.

W. Wen, C. Forman, and S. Jarvenpaa. Standards as a knowledge source for r\&d: A first look at their incidence and impacts based on the inventor survey and patent bibliographic data. Discussion Paper No. 11018, Research Institute of Economy, Trade and Industry (RIETI), 2014.

P. Werhane and J. Doering. Conflicts of interest and conflicts of commitment. Professional Ethics, A Multidisciplinary Journal, 4(3/4):47-81, 1995.

R. Werle. Institutional aspects of standardization-jurisdictional conflicts and the choice of standardization organizations. Journal of European Public Policy, 8(3):392-410, 2001.

J. Yates and C. N. Murphy. Engineering Rules: Global Standard Setting since 1880. JHU Press, 2019.

N. Zingales and O. Kanevskaia. The ieee-sa patent policy update under the lens of eu competition law. European Competition Journal, 12(2-3):195-235, 2016. 


\section{A Appendices}

A.1 Appendix 1: Descriptive Statistics 


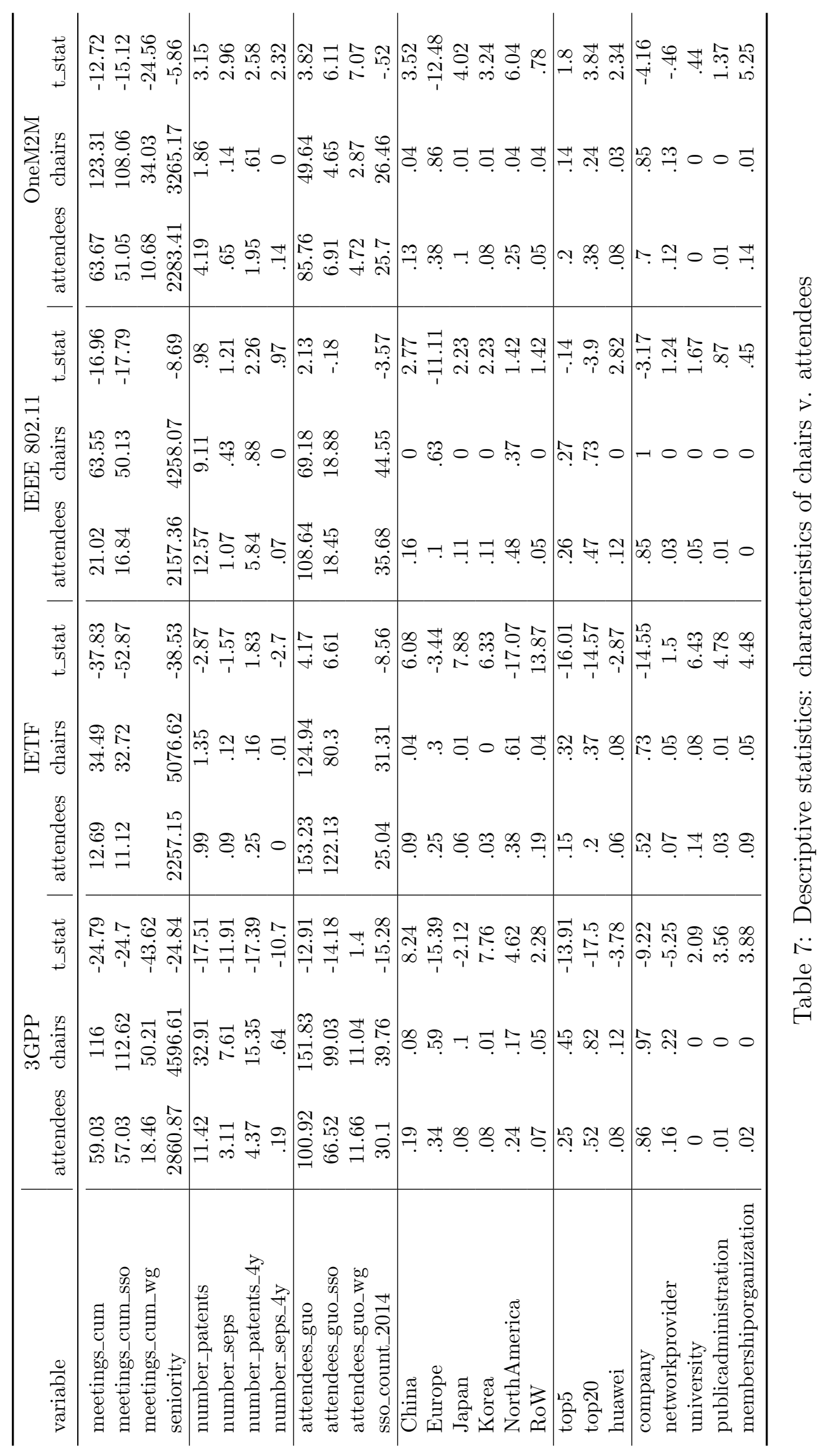




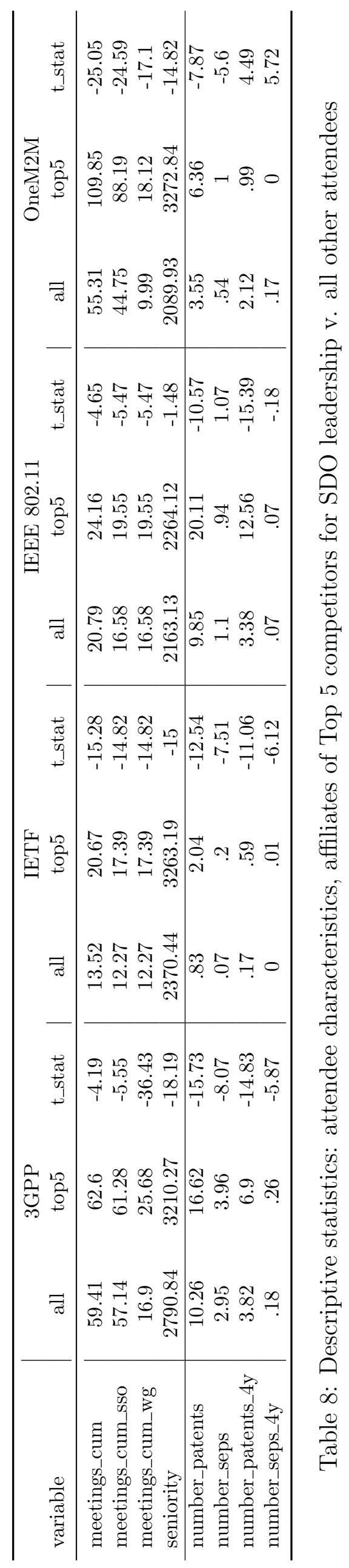




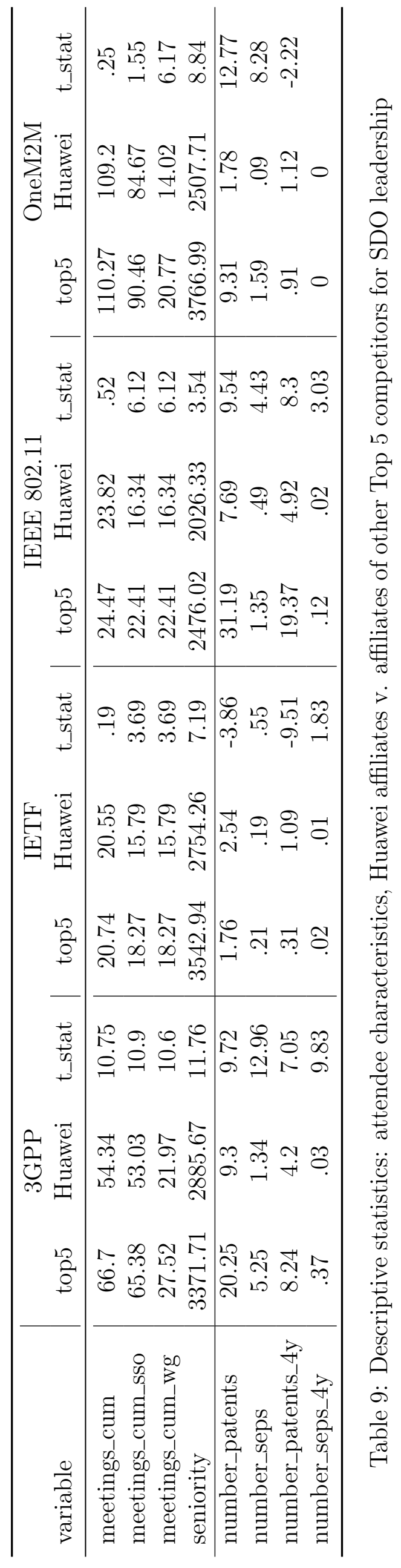




\section{A.2 Appendix 2: Affiliation mobility and attendee cohorts}

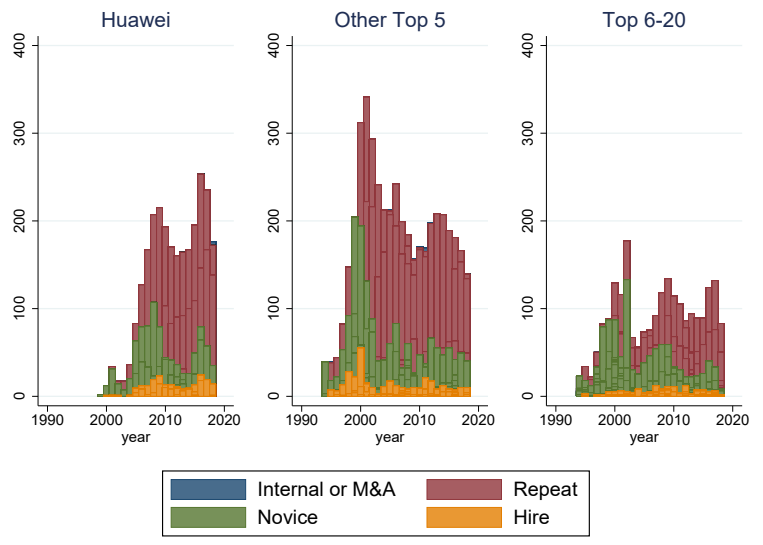

(a) All SDOs, by affiliation

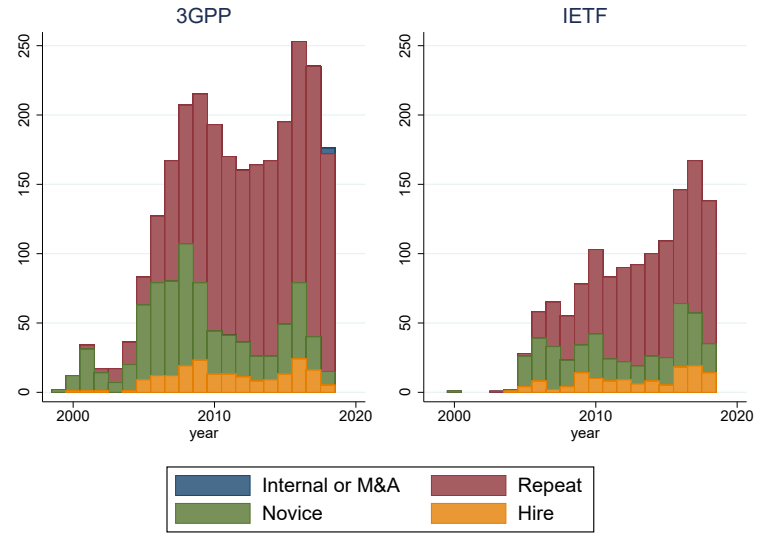

(b) Huawei affiliates, by SDO

Figure 5: Composition of attendee population cohorts - by affiliation group and SDO

\begin{tabular}{|c|c|c|c|c|c|}
\hline & $\begin{array}{c}(1) \\
3 \mathrm{GPP} \\
\text { mean/sd/count }\end{array}$ & $\begin{array}{c}(2) \\
\text { IEEE } 802.11 \\
\text { mean/sd/count }\end{array}$ & $\begin{array}{c}(3) \\
\text { IETF } \\
\text { mean/sd/count }\end{array}$ & $\begin{array}{c}(4) \\
\text { OneM2M } \\
\text { mean/sd/count }\end{array}$ & $\begin{array}{c}(5) \\
\text { All SDOs } \\
\text { mean/sd/count }\end{array}$ \\
\hline \multirow[t]{3}{*}{ Huawei } & 0.228 & 0.260 & 0.279 & 0.091 & 0.243 \\
\hline & 0.420 & 0.441 & 0.449 & 0.291 & 0.429 \\
\hline & 854 & 104 & 498 & 44 & 1,500 \\
\hline \multirow[t]{3}{*}{ Top 5, excl. Huawei } & 0.127 & 0.220 & 0.228 & 0.233 & 0.179 \\
\hline & 0.333 & 0.416 & 0.420 & 0.427 & 0.384 \\
\hline & 2,245 & 132 & 2,232 & 43 & 4,652 \\
\hline \multirow[t]{3}{*}{ Top 6-20 } & 0.130 & 0.139 & 0.138 & 0.103 & 0.133 \\
\hline & 0.337 & 0.346 & 0.345 & 0.306 & 0.340 \\
\hline & 4,054 & 317 & 2,379 & 145 & 6,895 \\
\hline \multirow[t]{3}{*}{ Total } & 0.141 & 0.181 & 0.191 & 0.125 & 0.162 \\
\hline & 0.348 & 0.385 & 0.393 & 0.331 & 0.369 \\
\hline & 7,153 & 553 & 5,109 & 232 & 13,047 \\
\hline
\end{tabular}

Table 10: Percentage of an affiliation's new attendees with previous SDO experience - by affiliation group and SDO 


\begin{tabular}{|c|c|c|c|c|c|}
\hline & $\begin{array}{c}\text { (1) } \\
3 \mathrm{GPP} \\
\text { mean/sd/count }\end{array}$ & $\begin{array}{c}(2) \\
\text { IEEE } 802.11 \\
\text { mean/sd/count }\end{array}$ & $\begin{array}{c}(3) \\
\text { IETF } \\
\text { mean/sd/count }\end{array}$ & $\begin{array}{c}(4) \\
\text { OneM2M } \\
\text { mean/sd/count }\end{array}$ & $\begin{array}{c}(5) \\
\text { All SDOs } \\
\text { mean/sd/count }\end{array}$ \\
\hline \multirow[t]{3}{*}{ Huawei } & 0.021 & 0.000 & 0.000 & 0.000 & 0.011 \\
\hline & 0.142 & 0.000 & 0.000 & 0.000 & 0.104 \\
\hline & 195 & 27 & 139 & 4 & 365 \\
\hline \multirow[t]{3}{*}{ Top 5, excl. Huawei } & 0.122 & 0.276 & 0.143 & 0.500 & 0.145 \\
\hline & 0.328 & 0.455 & 0.351 & 0.527 & 0.352 \\
\hline & 286 & 29 & 510 & 10 & 835 \\
\hline \multirow[t]{3}{*}{ Top 6-20 } & 0.166 & 0.045 & 0.170 & 0.067 & 0.160 \\
\hline & 0.373 & 0.211 & 0.376 & 0.258 & 0.367 \\
\hline & 529 & 44 & 329 & 15 & 917 \\
\hline \multirow[t]{3}{*}{ Total } & 0.126 & 0.100 & 0.132 & 0.207 & 0.128 \\
\hline & 0.332 & 0.302 & 0.339 & 0.412 & 0.335 \\
\hline & 1,010 & 100 & 978 & 29 & 2,117 \\
\hline
\end{tabular}

Table 11: Individuals with previous SDO experience: share attributed to company M\&As - by affiliation group and SDO

\section{A.3 Appendix 3: Duration analysis - Effect of chair appointment on affiliation changes}

\section{A.4 Appendix 4: Effect of affiliation on chair appointments}




\begin{tabular}{|c|c|c|c|c|c|c|c|c|}
\hline \multirow{3}{*}{ chairedgroups_3GPP } & \multirow{2}{*}{\multicolumn{2}{|c|}{$\begin{array}{ll} & (2) \\
& \text { Cox }\end{array}$}} & \multirow{2}{*}{\multicolumn{2}{|c|}{${ }^{(3)}$ CR: Top $5^{(4)}$}} & \multirow{2}{*}{\multicolumn{2}{|c|}{$\begin{array}{l}(5) \\
\text { CR: Huawei }\end{array}$}} & \multirow{2}{*}{\multicolumn{2}{|c|}{$\begin{array}{cc}(7) & (8) \\
\text { CR: Huawei;ex. China }\end{array}$}} \\
\hline & & & & & & & & \\
\hline & \multirow[t]{2}{*}{$\begin{array}{c}0.0611^{* * *} \\
(3.49)\end{array}$} & $\begin{array}{c}0.0595^{* *} \\
(2.91)\end{array}$ & \multirow[t]{2}{*}{$\begin{array}{c}0.0719^{*} \\
(2.13)\end{array}$} & $\begin{array}{c}0.0521 \\
(1.36)\end{array}$ & \multirow[t]{2}{*}{$\begin{array}{c}0.0675 \\
(1.28)\end{array}$} & $\begin{array}{c}0.0579 \\
(1.11)\end{array}$ & \multirow[t]{2}{*}{$\begin{array}{c}0.0681 \\
(1.30)\end{array}$} & $\begin{array}{c}0.0523 \\
(0.98)\end{array}$ \\
\hline active_chair_positions & & $\begin{array}{l}0.00756 \\
(0.16)\end{array}$ & & $\begin{array}{c}0.0852 \\
(1.33)\end{array}$ & & $\begin{array}{c}0.0470 \\
(0.47)\end{array}$ & & $\begin{array}{c}0.0771 \\
(0.91)\end{array}$ \\
\hline attendance_cumul & $\begin{array}{c}0.00422^{* * *} \\
(5.16)\end{array}$ & $\begin{array}{c}0.00422^{* * *} \\
\quad(5.16)\end{array}$ & $\begin{array}{c}0.00411^{* *} \\
(2.96)\end{array}$ & $\begin{array}{l}0.00409^{* *} \\
\quad(2.95)\end{array}$ & $\begin{array}{c}0.00298 \\
(1.37)\end{array}$ & $\begin{array}{c}0.00297 \\
(1.36)\end{array}$ & $\begin{array}{c}0.00326 \\
(1.57)\end{array}$ & $\begin{array}{c}0.00325 \\
(1.57)\end{array}$ \\
\hline seniority & $\begin{array}{c}-0.0000518^{*} \\
(-2.40)\end{array}$ & $\begin{array}{c}-0.0000517^{*} \\
(-2.40)\end{array}$ & $\begin{array}{l}0.0000192 \\
(0.41)\end{array}$ & $\begin{array}{l}0.0000201 \\
(0.42)\end{array}$ & $\begin{array}{l}0.0000547 \\
(0.79)\end{array}$ & $\begin{array}{l}0.0000554 \\
(0.80)\end{array}$ & $\begin{array}{c}0.00000841 \\
(0.12)\end{array}$ & $\begin{array}{c}0.00000992 \\
(0.14)\end{array}$ \\
\hline patent_count & $\begin{array}{c}0.00437^{*} \\
(2.11)\end{array}$ & $\begin{array}{c}0.00436^{*} \\
(2.11)\end{array}$ & $\begin{array}{c}0.00657 \\
(1.91)\end{array}$ & $\begin{array}{c}0.00651 \\
(1.89)\end{array}$ & $\begin{array}{c}0.00830^{*} \\
(2.03)\end{array}$ & $\begin{array}{c}0.00827^{*} \\
(2.02)\end{array}$ & $\begin{array}{c}0.00505 \\
(0.98)\end{array}$ & $\begin{array}{c}0.00498 \\
(0.97)\end{array}$ \\
\hline sep_count & $\begin{array}{c}-0.0177^{* *} \\
(-2.86)\end{array}$ & $\begin{array}{c}-0.0177^{* *} \\
(-2.86)\end{array}$ & $\begin{array}{c}-0.0209 \\
(-1.55)\end{array}$ & $\begin{array}{c}-0.0207 \\
(-1.54)\end{array}$ & $\begin{array}{c}-0.0185 \\
(-1.03)\end{array}$ & $\begin{array}{c}-0.0184 \\
(-1.02)\end{array}$ & $\begin{array}{c}-0.0127 \\
(-0.61)\end{array}$ & $\begin{array}{c}-0.0126 \\
(-0.60)\end{array}$ \\
\hline China & $\begin{array}{c}0.325^{*} \\
(2.50)\end{array}$ & $\begin{array}{c}0.324^{*} \\
(2.50)\end{array}$ & $\begin{array}{c}0.797^{* *} \\
(2.60)\end{array}$ & $\begin{array}{c}0.797^{* *} \\
(2.60)\end{array}$ & $\begin{array}{c}1.897^{* * *} \\
(3.68)\end{array}$ & $\begin{array}{c}1.896^{* * *} \\
(3.67)\end{array}$ & $\begin{array}{c}0 \\
(.)\end{array}$ & $\begin{array}{l}0 \\
(.)\end{array}$ \\
\hline Europe & $\begin{array}{l}-0.136 \\
(-1.09)\end{array}$ & $\begin{array}{l}-0.136 \\
(-1.09)\end{array}$ & $\begin{array}{c}0.0502 \\
(0.16)\end{array}$ & $\begin{array}{c}0.0467 \\
(0.15)\end{array}$ & $\begin{array}{l}0.433 \\
(0.82)\end{array}$ & $\begin{array}{l}0.431 \\
(0.81)\end{array}$ & $\begin{array}{l}0.595 \\
(1.12)\end{array}$ & $\begin{array}{l}0.591 \\
(1.11)\end{array}$ \\
\hline Japan & $\begin{array}{c}-0.744^{* * *} \\
(-4.49)\end{array}$ & $\begin{array}{c}-0.744^{* * *} \\
(-4.49)\end{array}$ & $\begin{array}{c}-1.181^{*} \\
(-2.46)\end{array}$ & $\begin{array}{c}-1.183^{*} \\
(-2.46)\end{array}$ & $\begin{array}{l}-1.285 \\
(-1.47)\end{array}$ & $\begin{array}{l}-1.286 \\
(-1.47)\end{array}$ & $\begin{array}{l}-1.137 \\
(-1.30)\end{array}$ & $\begin{array}{l}-1.139 \\
(-1.30)\end{array}$ \\
\hline Korea & $\begin{array}{c}-0.335^{*} \\
(-2.03)\end{array}$ & $\begin{array}{c}-0.335^{*} \\
(-2.04)\end{array}$ & $\begin{array}{c}-1.347^{*} \\
(-2.33)\end{array}$ & $\begin{array}{c}-1.348^{*} \\
(-2.33)\end{array}$ & $\begin{array}{c}-13.60^{* * *} \\
(-27.08)\end{array}$ & $\begin{array}{c}-13.61^{* * *} \\
(-27.07)\end{array}$ & $\begin{array}{c}-14.99^{* * *} \\
(-29.79)\end{array}$ & $\begin{array}{c}-14.99^{* * *} \\
(-29.78)\end{array}$ \\
\hline North America & $\begin{array}{c}0.364^{* *} \\
(2.93)\end{array}$ & $\begin{array}{c}0.364^{* *} \\
(2.93)\end{array}$ & $\begin{array}{c}0.616^{*} \\
(2.04)\end{array}$ & $\begin{array}{c}0.613^{*} \\
(2.03)\end{array}$ & $\begin{array}{l}0.764 \\
(1.45)\end{array}$ & $\begin{array}{l}0.762 \\
(1.44)\end{array}$ & $\begin{array}{l}0.853 \\
(1.62)\end{array}$ & $\begin{array}{l}0.849 \\
(1.61)\end{array}$ \\
\hline year & $\begin{array}{c}-0.0290^{* * *} \\
(-4.88)\end{array}$ & $\begin{array}{c}-0.0289^{* * *} \\
(-4.88)\end{array}$ & $\begin{array}{c}-0.0248 \\
(-1.88)\end{array}$ & $\begin{array}{c}-0.0245 \\
(-1.86)\end{array}$ & $\begin{array}{c}0.00791 \\
(0.40)\end{array}$ & $\begin{array}{c}0.00810 \\
(0.41)\end{array}$ & $\begin{array}{c}0.0498^{*} \\
(2.36)\end{array}$ & $\begin{array}{c}0.0502^{*} \\
(2.38)\end{array}$ \\
\hline subjects & 7,622 & 7,622 & 7,622 & 7,622 & 7,180 & 7,180 & 6,355 & 6,355 \\
\hline Failures & 1,686 & 1,686 & 331 & 331 & 155 & 155 & 100 & 100 \\
\hline Competing & & & 1,355 & 1,355 & 1,455 & 1,455 & 1,282 & 1,282 \\
\hline
\end{tabular}

$t$ statistics in parentheses

${ }^{*} p<0.05,{ }^{* *} p<0.01,{ }^{* * *} p<0.001$

Table 12: Effect of appointment to chair positions on affiliation changes $3 \mathrm{GPP}$ 


\begin{tabular}{|c|c|c|c|c|c|c|c|c|}
\hline \multirow{3}{*}{ chairedgroups } & \multirow{2}{*}{\multicolumn{2}{|c|}{ (2) }} & \multirow{2}{*}{\multicolumn{2}{|c|}{${ }^{(3)}$ CR: Top $5^{(4)}$}} & \multirow{2}{*}{\multicolumn{2}{|c|}{$\begin{array}{l}(5) \\
\text { CR: Huawei }\end{array}$}} & \multirow{2}{*}{\multicolumn{2}{|c|}{$\begin{array}{cl}(7) & (8) \\
\text { CR: Huawei;ex. China }\end{array}$}} \\
\hline & & & & & & & & \\
\hline & \multirow[t]{2}{*}{$\begin{array}{c}0.0231^{*} \\
(2.12)\end{array}$} & $\begin{array}{l}0.0250 \\
(1.96)\end{array}$ & \multirow[t]{2}{*}{$\begin{array}{c}0.0960^{* * *} \\
(3.79)\end{array}$} & $\begin{array}{c}0.0856^{* *} \\
(2.95)\end{array}$ & $\begin{array}{l}0.109^{*} \\
(1.98)\end{array}$ & $\begin{array}{l}0.106 \\
(1.74)\end{array}$ & \multirow[t]{2}{*}{$\begin{array}{l}0.108 \\
(1.87)\end{array}$} & $\begin{array}{l}0.102 \\
(1.56)\end{array}$ \\
\hline active_chair_positions & & $\begin{array}{c}-0.00739 \\
(-0.29)\end{array}$ & & $\begin{array}{c}0.0436 \\
(0.94)\end{array}$ & & $\begin{array}{c}0.00915 \\
(0.13)\end{array}$ & & $\begin{array}{l}0.0227 \\
(0.35)\end{array}$ \\
\hline attendance_cumul & $\begin{array}{l}0.0200^{* * *} \\
\quad(6.07)\end{array}$ & $\begin{array}{l}0.0201^{* * *} \\
\quad(6.08)\end{array}$ & $\begin{array}{c}0.00957 \\
(0.95)\end{array}$ & $\begin{array}{c}0.00913 \\
(0.90)\end{array}$ & $\begin{array}{c}0.0148 \\
(0.83)\end{array}$ & $\begin{array}{l}0.0147 \\
(0.82)\end{array}$ & $\begin{array}{c}0.0151 \\
(0.81)\end{array}$ & $\begin{array}{c}0.0150 \\
(0.81)\end{array}$ \\
\hline seniority & $\begin{array}{c}-0.0000790^{* * *} \\
(-4.28)\end{array}$ & $\begin{array}{c}-0.0000792^{* * *} \\
(-4.28)\end{array}$ & $\begin{array}{c}-0.0000274 \\
(-0.46)\end{array}$ & $\begin{array}{c}-0.0000260 \\
(-0.43)\end{array}$ & $\begin{array}{c}-0.0000853 \\
(-0.78)\end{array}$ & $\begin{array}{c}-0.0000850 \\
(-0.78)\end{array}$ & $\begin{array}{c}-0.0000713 \\
(-0.61)\end{array}$ & $\begin{array}{c}-0.0000704 \\
(-0.60)\end{array}$ \\
\hline patent_count & $\begin{array}{l}0.00785^{*} \\
(2.22)\end{array}$ & $\begin{array}{l}0.00784^{*} \\
(2.21)\end{array}$ & $\begin{array}{l}0.0187^{* * *} \\
\quad(4.20)\end{array}$ & $\begin{array}{c}0.0187^{* * *} \\
\quad(4.21)\end{array}$ & $\begin{array}{c}0.0156^{* *} \\
(2.66)\end{array}$ & $\begin{array}{c}0.0156^{* *} \\
(2.66)\end{array}$ & $\begin{array}{c}0.0280^{* * *} \\
(4.13)\end{array}$ & $\begin{array}{c}0.0280^{* * *} \\
\quad(4.13)\end{array}$ \\
\hline sep_count & $\begin{array}{c}-0.0165 \\
(-1.20)\end{array}$ & $\begin{array}{c}-0.0165 \\
(-1.20)\end{array}$ & $\begin{array}{c}-0.0273 \\
(-1.31)\end{array}$ & $\begin{array}{c}-0.0273 \\
(-1.31)\end{array}$ & $\begin{array}{c}-0.0265 \\
(-1.06)\end{array}$ & $\begin{array}{c}-0.0265 \\
(-1.06)\end{array}$ & $\begin{array}{c}-0.0486 \\
(-1.70)\end{array}$ & $\begin{array}{c}-0.0486 \\
(-1.70)\end{array}$ \\
\hline China & $\begin{array}{c}-0.0752 \\
(-0.55)\end{array}$ & $\begin{array}{c}-0.0755 \\
(-0.55)\end{array}$ & $\begin{array}{c}1.519^{* * *} \\
(3.46)\end{array}$ & $\begin{array}{c}1.520^{* * *} \\
(3.46)\end{array}$ & $\begin{array}{c}2.344^{* * *} \\
(3.82)\end{array}$ & $\begin{array}{c}2.344^{* * *} \\
(3.81)\end{array}$ & $\begin{array}{c}0 \\
(.)\end{array}$ & $\begin{array}{l}0 \\
(.)\end{array}$ \\
\hline Europe & $\begin{array}{c}-0.263^{*} \\
(-2.43)\end{array}$ & $\begin{array}{c}-0.262^{*} \\
(-2.43)\end{array}$ & $\begin{array}{l}0.691 \\
(1.65)\end{array}$ & $\begin{array}{l}0.688 \\
(1.64)\end{array}$ & $\begin{array}{l}0.235 \\
(0.38)\end{array}$ & $\begin{array}{l}0.234 \\
(0.38)\end{array}$ & $\begin{array}{l}0.275 \\
(0.44)\end{array}$ & $\begin{array}{l}0.273 \\
(0.44)\end{array}$ \\
\hline Japan & $\begin{array}{c}-0.577^{* * *} \\
(-4.39)\end{array}$ & $\begin{array}{c}-0.577^{* * *} \\
(-4.40)\end{array}$ & $\begin{array}{l}-1.082 \\
(-1.68)\end{array}$ & $\begin{array}{l}-1.081 \\
(-1.68)\end{array}$ & $\begin{array}{c}-14.38^{* * *} \\
(-24.70)\end{array}$ & $\begin{array}{c}-14.38^{* * *} \\
(-24.69)\end{array}$ & $\begin{array}{c}-17.14^{* * *} \\
(-28.89)\end{array}$ & $\begin{array}{c}-17.14^{* * *} \\
(-28.87)\end{array}$ \\
\hline Korea & $\begin{array}{c}-0.593^{* *} \\
(-3.17)\end{array}$ & $\begin{array}{c}-0.593^{* *} \\
(-3.17)\end{array}$ & $\begin{array}{c}-13.36^{* * *} \\
(-32.06)\end{array}$ & $\begin{array}{c}-13.36^{* * *} \\
(-32.02)\end{array}$ & $\begin{array}{c}-14.40^{* * *} \\
(-24.20)\end{array}$ & $\begin{array}{c}-14.40^{* * *} \\
(-24.19)\end{array}$ & $\begin{array}{c}-17.37^{* * *} \\
(-28.88)\end{array}$ & $\begin{array}{c}-17.37^{* * *} \\
(-28.87)\end{array}$ \\
\hline North America & $\begin{array}{c}-0.0186 \\
(-0.18)\end{array}$ & $\begin{array}{c}-0.0183 \\
(-0.18)\end{array}$ & $\begin{array}{l}0.744 \\
(1.81)\end{array}$ & $\begin{array}{l}0.741 \\
(1.80)\end{array}$ & $\begin{array}{l}0.332 \\
(0.55)\end{array}$ & $\begin{array}{l}0.331 \\
(0.54)\end{array}$ & $\begin{array}{l}0.365 \\
(0.60)\end{array}$ & $\begin{array}{l}0.363 \\
(0.60)\end{array}$ \\
\hline year & $\begin{array}{c}-0.0367^{* * *} \\
(-8.97)\end{array}$ & $\begin{array}{c}-0.0367^{* * *} \\
(-8.97)\end{array}$ & $\begin{array}{c}-0.0164 \\
(-1.51)\end{array}$ & $\begin{array}{c}-0.0166 \\
(-1.52)\end{array}$ & $\begin{array}{c}0.0744^{* * * *} \\
(4.08)\end{array}$ & $\begin{array}{c}0.0744^{* * *} \\
(4.07)\end{array}$ & $\begin{array}{c}0.0970^{* * *} \\
(4.96)\end{array}$ & $\begin{array}{c}0.0969^{* * *} \\
(4.94)\end{array}$ \\
\hline $\mathrm{N}$ & 60,093 & 60,093 & 60,093 & 60,093 & 57,004 & 57,004 & 54,864 & 54,864 \\
\hline subjects & 6,354 & 6,354 & 6,354 & 6,354 & 6,124 & 6,124 & 5,873 & 5,873 \\
\hline Failures & 2,288 & 2,288 & 282 & 282 & 94 & 94 & 66 & 66 \\
\hline Competing & & & 2,006 & 2,006 & 2,145 & 2,145 & 2,083 & 2,083 \\
\hline
\end{tabular}

$t$ statistics in parentheses

${ }^{*} p<0.05,{ }^{* *} p<0.01,{ }^{* * *} p<0.001$

Table 13: Effect of appointment to chair positions on affiliation changes IETF 


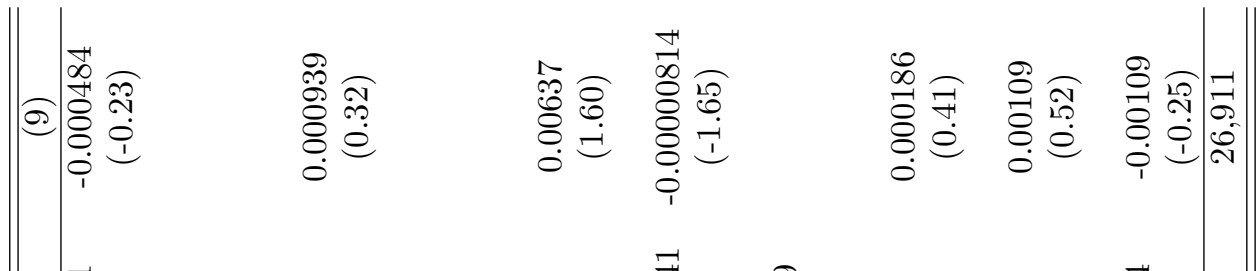

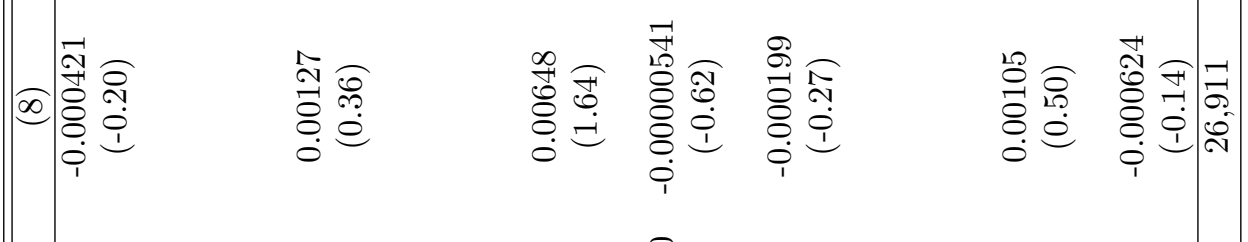

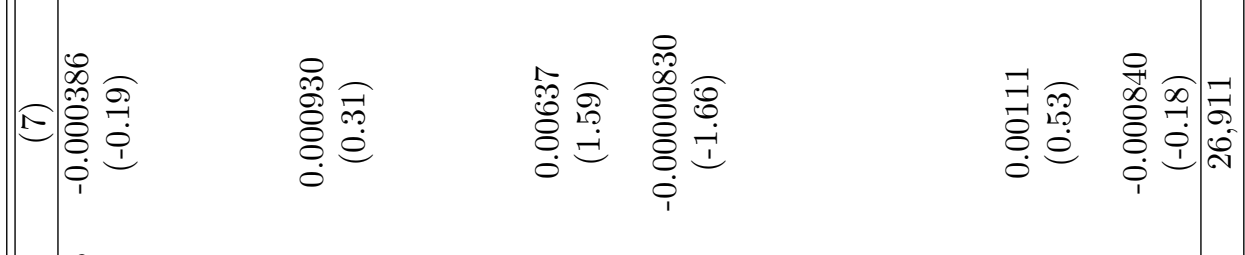

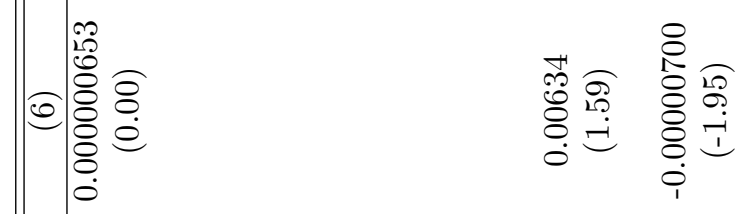

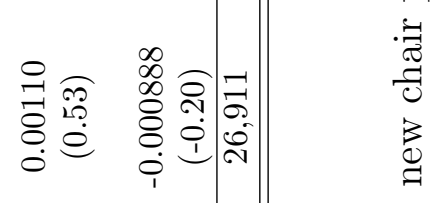

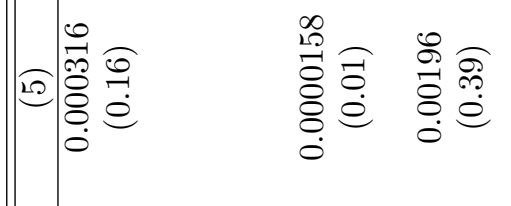

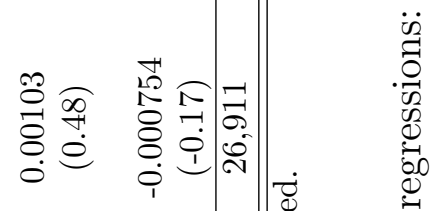

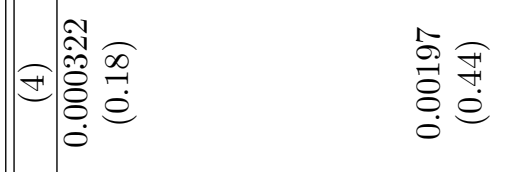

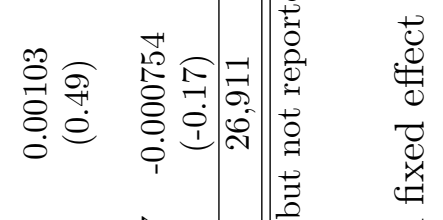

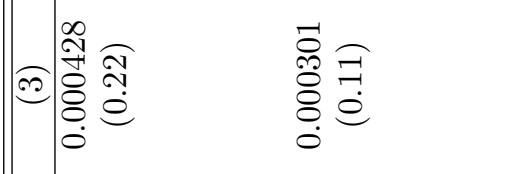

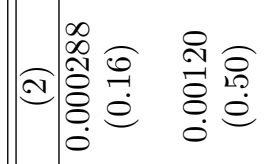

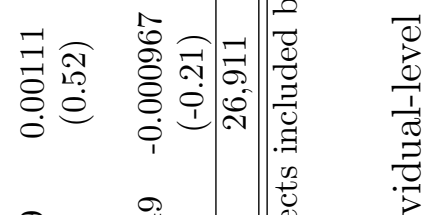

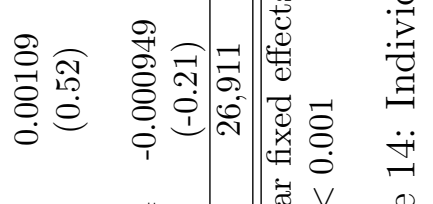

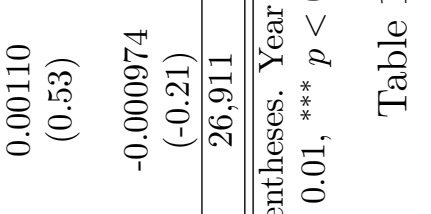<smiles>C1CC2CC12</smiles> 


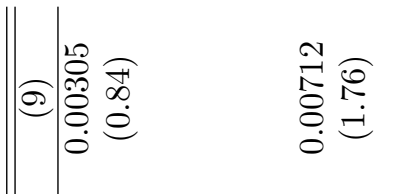

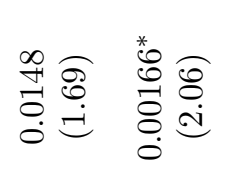

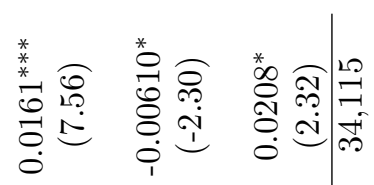

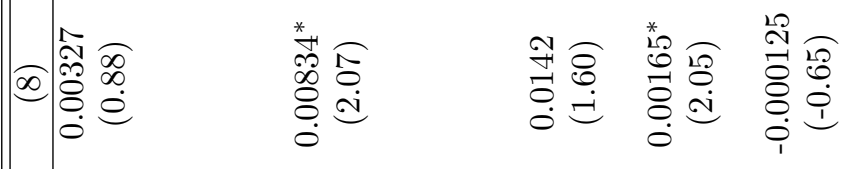

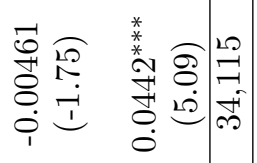

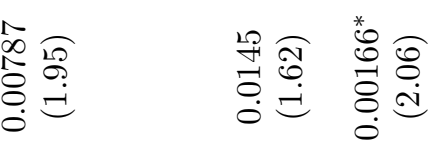

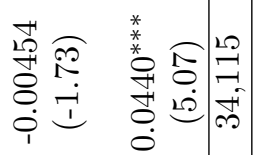

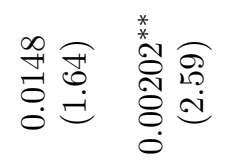

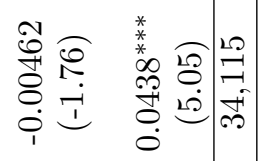
鼠

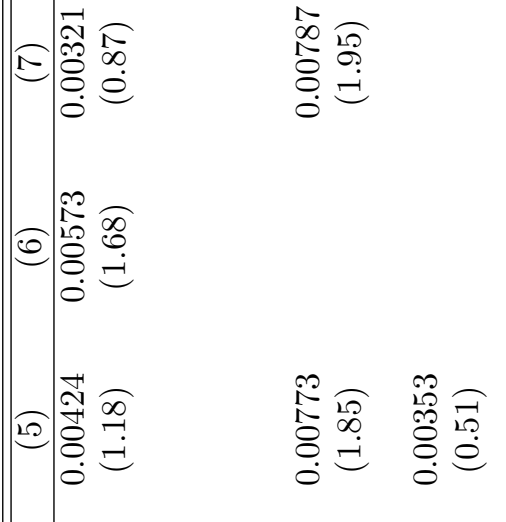

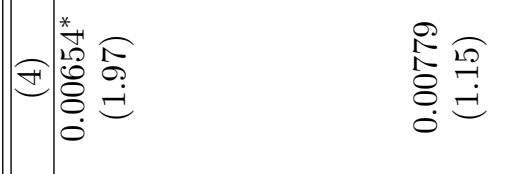

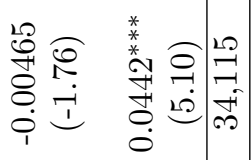

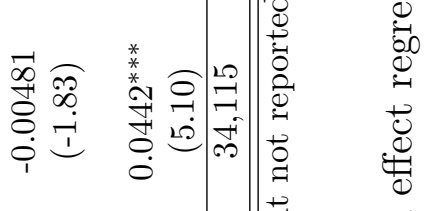

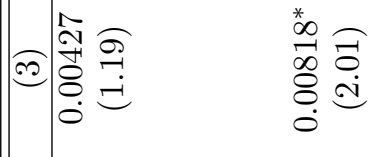

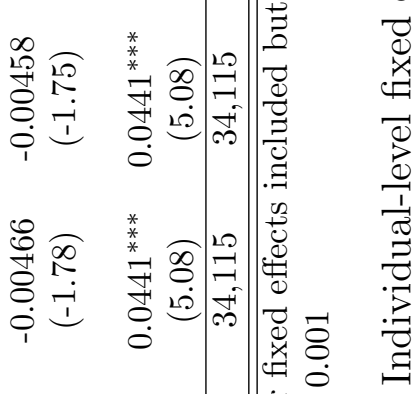

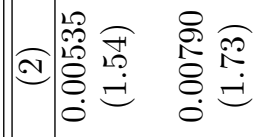

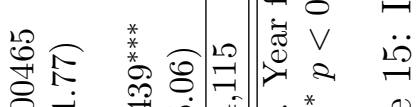
䣻
,

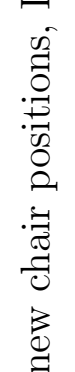

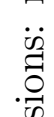




\begin{tabular}{|c|c|c|c|c|c|c|}
\hline & $(1)$ & $(2)$ & (3) & (4) & $(5)$ & (6) \\
\hline top5 & $\begin{array}{c}-0.00191 \\
(-0.93)\end{array}$ & & & & & \\
\hline top20 & & $\begin{array}{c}0.00496 \\
(1.27)\end{array}$ & & & & \\
\hline huawei & & & $\begin{array}{c}0.00436^{*} \\
(1.98)\end{array}$ & & & \\
\hline network_op & & & & $\begin{array}{c}0.0106 \\
(1.52)\end{array}$ & & \\
\hline \#decl_SEP & & & & & $\begin{array}{c}-0.00000660 \\
(-1.28)\end{array}$ & \\
\hline company & & & & & & $\begin{array}{c}-0.00832^{* *} \\
(-2.87)\end{array}$ \\
\hline after & $\begin{array}{c}0.00491 \\
(1.11)\end{array}$ & $\begin{array}{c}0.00493 \\
(1.12)\end{array}$ & $\begin{array}{c}0.00467 \\
(1.06)\end{array}$ & $\begin{array}{c}0.00479 \\
(1.09)\end{array}$ & $\begin{array}{c}0.00474 \\
(1.09)\end{array}$ & $\begin{array}{c}0.00477 \\
(1.09)\end{array}$ \\
\hline seniority & $\begin{array}{c}-0.00000341 \\
(-1.15)\end{array}$ & $\begin{array}{c}-0.00000342 \\
(-1.15)\end{array}$ & $\begin{array}{c}-0.00000346 \\
(-1.17)\end{array}$ & $\begin{array}{c}-0.00000337 \\
(-1.13)\end{array}$ & $\begin{array}{c}-0.00000318 \\
(-1.09)\end{array}$ & $\begin{array}{c}-0.00000350 \\
(-1.18)\end{array}$ \\
\hline _cons & $\begin{array}{c}0.0118^{* *} \\
(2.83)\end{array}$ & $\begin{array}{c}0.00924^{*} \\
(2.49)\end{array}$ & $\begin{array}{c}0.0113^{* *} \\
(2.80)\end{array}$ & $\begin{array}{c}0.0103^{*} \\
(2.46)\end{array}$ & $\begin{array}{c}0.0116^{* *} \\
(2.84)\end{array}$ & $\begin{array}{c}0.0189^{* * *} \\
(3.46)\end{array}$ \\
\hline$N$ & 22,180 & 22,180 & 22,180 & 22,134 & 22,180 & 22,134 \\
\hline Groups & 2,202 & 2,202 & 2,202 & 2,202 & 2,202 & 2,202 \\
\hline
\end{tabular}

$t$ statistics in parentheses

${ }^{*} p<0.05,{ }^{* *} p<0.01,{ }^{* * *} p<0.001$

Table 16: New chair appointments, before and after change of affiliation 6 year window - $3 \mathrm{GPP}$ 


\begin{tabular}{|c|c|c|c|c|c|c|}
\hline & $(1)$ & $(2)$ & $(3)$ & (4) & $(5)$ & $(6)$ \\
\hline top5 & $\begin{array}{c}0.00903^{* *} \\
(2.72)\end{array}$ & & & & & \\
\hline top20 & & $\begin{array}{c}0.00682^{*} \\
(2.55)\end{array}$ & & & & \\
\hline huawei & & & $\begin{array}{c}0.00427 \\
(0.60)\end{array}$ & & & \\
\hline network_op & & & & $\begin{array}{c}0.00616 \\
(1.48)\end{array}$ & & \\
\hline \#decl_SEP & & & & & $\begin{array}{c}0.0000382 \\
(0.06)\end{array}$ & \\
\hline company & & & & & & $\begin{array}{c}0.00438^{*} \\
(2.01)\end{array}$ \\
\hline after & $\begin{array}{c}-0.000680 \\
(-0.26)\end{array}$ & $\begin{array}{c}-0.000593 \\
(-0.23)\end{array}$ & $\begin{array}{c}-0.000379 \\
(-0.15)\end{array}$ & $\begin{array}{c}-0.000317 \\
(-0.12)\end{array}$ & $\begin{array}{c}-0.000317 \\
(-0.12)\end{array}$ & $\begin{array}{c}-0.000422 \\
(-0.16)\end{array}$ \\
\hline seniority & $\begin{array}{c}-0.000000154 \\
(-0.07)\end{array}$ & $\begin{array}{c}-7.81 \mathrm{e}-08 \\
(-0.04)\end{array}$ & $\begin{array}{c}-9.69 \mathrm{e}-08 \\
(-0.04)\end{array}$ & $\begin{array}{c}-5.07 \mathrm{e}-08 \\
(-0.02)\end{array}$ & $\begin{array}{c}-7.49 \mathrm{e}-08 \\
(-0.03)\end{array}$ & $\begin{array}{c}-9.52 \mathrm{e}-09 \\
(-0.00)\end{array}$ \\
\hline _cons & $\begin{array}{c}0.0159^{* * *} \\
(4.21)\end{array}$ & $\begin{array}{c}0.0153^{\text {*** }} \\
(4.02)\end{array}$ & $\begin{array}{c}0.0168^{* * *} \\
(4.50)\end{array}$ & $\begin{array}{c}0.0164^{* * *} \\
(4.40)\end{array}$ & $\begin{array}{c}0.0168^{* * *} \\
(4.51)\end{array}$ & $\begin{array}{c}0.0133^{* *} \\
(3.28)\end{array}$ \\
\hline$N$ & 35,062 & 35,062 & 35,062 & 35,053 & 35,062 & 35,053 \\
\hline Groups & 3,567 & 3,567 & 3,567 & 3,567 & 3,567 & 3,567 \\
\hline
\end{tabular}

Table 17: New chair appointments, before and after change of affiliation 6 year window - IETF 